\title{
Max Beckmanns Strand- und Meeres-Gemälde bis zur Emigration nach Amsterdam 1937
}

Im Juni 1942 schrieb der Maler Jules Bissier an Oskar Schlemmer: „Diesem Leben muß man sich anvertrauen wie einem Kahn, der ohne Steuer und Segel in der Nacht über ein unberechenbares Gewässer führt. Immer in dem Gedanken, daß auch die Schlünde, Abgründe und Strudel Wege des Lebens sind. Nach dem Tode? Wer weiß es? Sicher ist, daß der Einzelne nicht weiterlebt, aber weiterlebend teil hat an der Masse der lebenden Erde ... $\ll^{1}$

Mit diesen keineswegs christlichen, eher pantheistischen Worten suchte Bissier in einer dunklen Zeit der Herrschaft des Faschismus über Europa, der Zeit eines unglaublichen Angriffskrieges der Nazi-Deutschen gegen das übrige Europa, eine Art metaphorisches Gleichnis für seine Lebenssicht, quasi für das Leben schlechthin. Innerhalb dieses bildhaften Vergleichs fällt die Dominanz des Heraklitismus auf, ${ }^{2}$ d. h. daß das Leben einem dunklen Gewässer gleichgestellt ist, einem Strom, an dem der Mensch passiv teilhat, auf dem sich der lebende Einzelne in einem Boot aller Unbestimmtheit und Dunkelheit ausgeliefert fühlt. Oder anders gesagt: Betont wird die Bewegung innerhalb eines unbekannten fließenden Elements, der kein Ziel entnommen werden kann und welcher der Lebende blind involviert scheint. Entsprechend schrieb Hans Blumenberg in seinem Essay von 1979 »Schiffbruch mit Zuschauer«: »Unter den elementarsten Realitäten, mit denen es der Mensch zu tun hat, ist ihm die des Meeres ... die am wenigsten geheure. $\star^{3}$

Meines Erachtens stellt sich für die Behandlung der Meeres- und Strand-Bilder Beckmanns jeden-

\footnotetext{
${ }^{1}$ Hagnau 4. Juni 1942, in: M. Bärmann (Hg.), Julius Bissier - Oskar Schlemmer Briefwechsel, St. Gallen 1988, 87.

${ }^{2}$ Zum Begriff des modernen Heraklitismus vgl. Georg Simmel, REMBRANDT - ein kunstphilosophischer Ver-
}

falls die Frage, wie man vorgeht: eine Art systematische Untersuchung würde etwa nach »Konstanten « (wie U.Weisner) ${ }^{4}$ fragen und diachrone Vergleiche Beckmann'scher Gemälde präferieren; eine andere Methode wäre - dem historischen Denken verpflichtet - diejenige, die die Chronologie ins Zentrum rückt. Das aber würde eine Aneinanderreihung der Werke im biographischen Leitfaden bedeuten. Doch muß ich die Kenntnis der Biographie Beckmanns voraussetzen.

Da Ulrich Weisner u. a. Autoren bereits die Vergleiche verschiedenzeitlich entstandener Werke vorgeführt haben, versuche ich doch, der Chronologie prinzipiell den Vorzug zu lassen, gehe aber nicht einfach von der Biographie aus sondern vielmehr von der Signifikanz bestimmter Meeres-Bilder. Diese Methode hat zumindest den Vorteil, ein wichtiges Kriterium des Kunstprozesses nicht zu nivellieren, nämlich daß ein Werk des Künstlers den vorherigen folgt, daß Wandlungen innerhalb des Schaffen, ausgelöst durch soziale Lage und Krisen, schließlich aufbauen auf den schon konkretisierten Werken. Das lebendige Prinzip des Wachsens - gerade eines künstlerischen Schaffens - bzw. des Aufbauens und Variierens wird somit relevanter als bei diachronen Vergleichen.

Der Künstler arbeitet Schritt für Schritt, trifft eine Auswahl aus der sichtbaren und unsichtbaren Realität für die ihn brennenden Sujets, primär für sich selbst d. h. »monologisch «, wie Nietzsche dies nannte; er bannt ein Stück Wirklichkeit, gestaltet es subjektiv und deutet somit diese Wirklichkeit, die er auswählt, für sich und für die Mitwelt. »Der Künstler wählt seine Stoffe aus: das ist

such, 2. A. Leipzig 1919, 134; W. Gebhard, Nietzsches Totalismus, Berlin/New York 1983, 7of.

${ }^{3}$ Hans Blumenberg, Schiffbruch mit Zuschauer, Frankfurt/M. 1979, 9. 


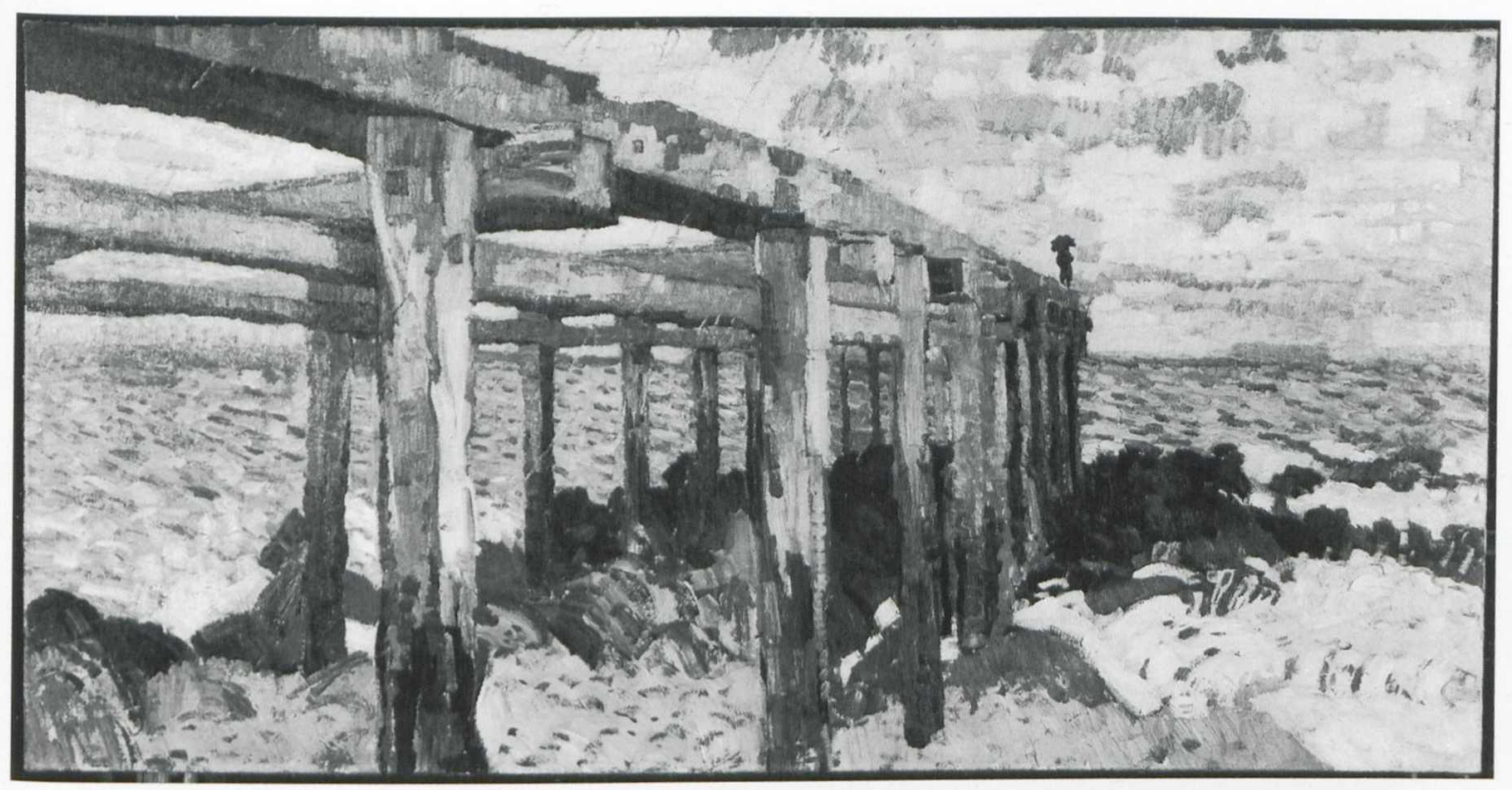

I. Max Beckmann: Große Buhne, 1905, Leipzig, Museum der bildenden Künste

seine Art zu loben«, konstatierte Nietzsche (Fröhliche Wissenschaft, no. 245). 5

Bevor ich mit frühen Meer-Bildern Beckmanns beginne, die erstaunlich oft auftreten, möchte ich aus der Tradition der Land- und Meeres-Bilder des i9. Jahrhunderts eine Gegenüberstellung machen, die polare Gegensätze zwischen asketischer und vitalistischer Haltung offenbart: ich meine C. D. Friedrichs "Mönch am Meer« (I809) und Courbets 1854 im Midi gemaltes "La mer à Palavas" (Montpellier), im Vordergrund der Maler selbst. Werden bei Friedrich Himmel, Meer und seelische Verfassung des einsamen Menschen Ausdruck eines tiefgreifenden Pessimismus, ja Symbole des Todes nach Jean Pauls berühmter »Rede des toten Christus « (1789), so konkretisiert Courbet in seinem Gemälde mit dem Licht, dem grünen Meer, dem hellblauen Himmel, dem kom-

${ }^{4}$ Ulrich Weisner, Konstanten im Werk Max Beckmanns, in Kat. Max Beckmann - die frühen Bilder, Bielefeld 1982/Städel 1983, 157f.

${ }^{5}$ Auf die Rolle des Prinzips und der Wichtigkeit der Auswahl haben schon Th. Thoré-Bürger (Kunstschön- plementär in Gelbocker gemalten Strand und besonders durch die Leibsprache der Malerfigur, d. h. durch die emphatische Begrüßung des Meeres und seiner Schönheit, lebensphilosophisch den anderen Pol, nämlich statt lebensverneinender eine lebensbejahende Haltung, statt saturnischer Melancholie eine vitalistische Emphase, d. h. also eine »dionysische« Haltung. Sind beide Gemälde auch nicht zeitgleich, so können sie uns doch zwei polare Auffassungen der Menschen-Natur eröffnen, d.h. gegenüber dem Leben zwischen Geburt, Existenz und Tod und letztlich der Stellung des malenden Subjekts zum Objekt des Meeres als dem heraklitischen Symbol.

Der Bildvergleich läßt an die Unterscheidung Heinrich Heines zwischen sog. "Nazarenern « und "Hellenen « denken, d. h. zwischen den am Mangel des Lebens Leidenden und den an der

heit - Naturschönheit, 1845) und Albert Camus (Der Künstler und seine Zeit, Rede in Uppsala, I4. I2. 1957) hingewiesen. - Zur Unterscheidung von "monologischer Kunst « und »Kunst für Zeugen « vgl. Friedrich Nietzsche, Fröhliche Wissenschaft, 1886, No. 367. 


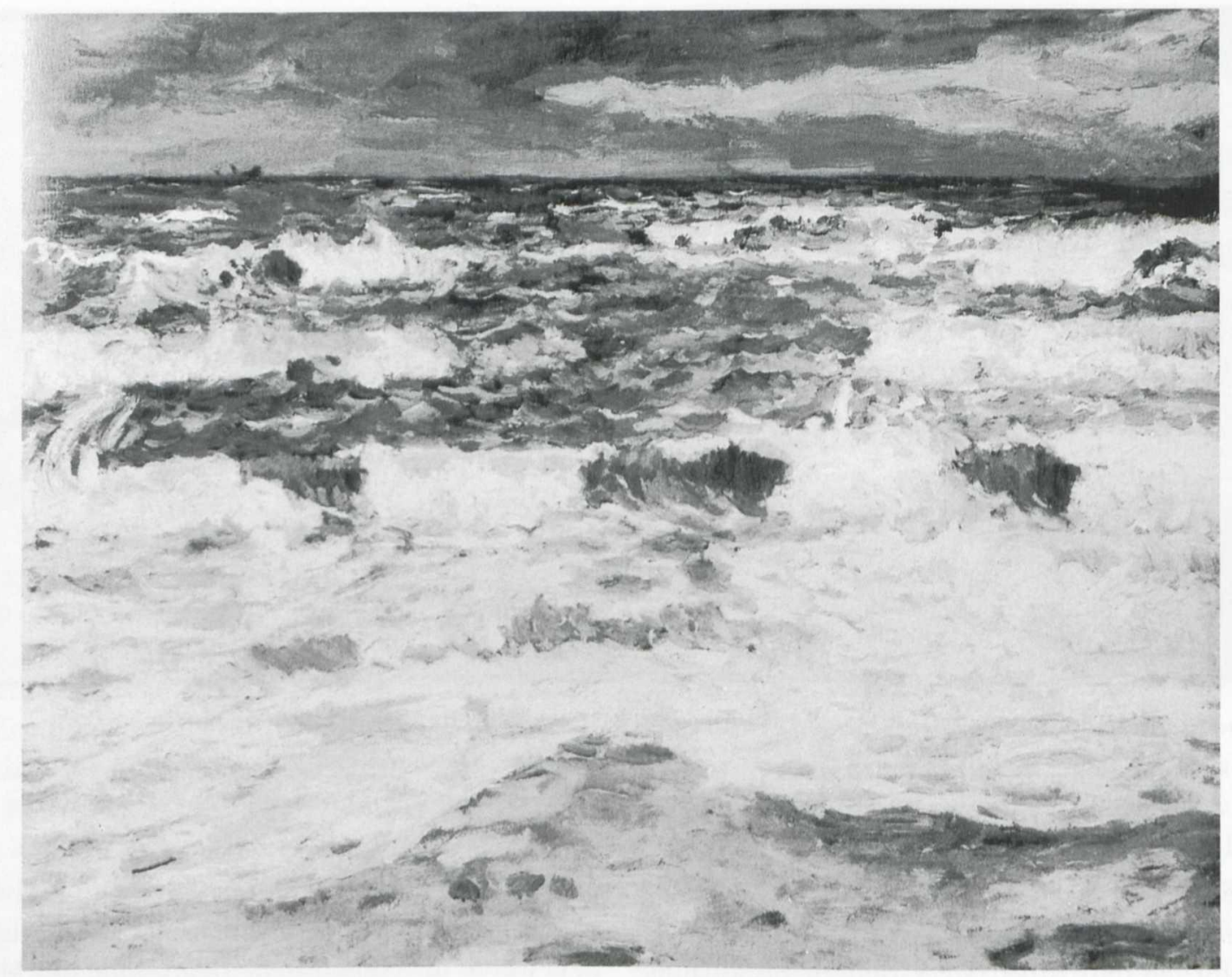

2. Max Beckmann: Seestück Ostsee, 1907,

St. Louis, The Saint Louis Art Museum

Überfülle und Schönheit des Lebens Teilhabenden. Heines Differenzierung (im I. Buch der Schrift über Ludwig Börne): die Menschen seien entweder solche "mit ascetischen, vergeistigungssüchtigen Trieben, oder (aber) Menschen von lebensheiterem, entfaltungsstolzem und realistischem Wesen ${ }^{6}{ }^{6}$

Max Beckmann suchte immer wieder das Meer auf - für ihn Element des Unendlichen und Symbol der fortzeugenden Wandlung. Dabei mitbestimmend war in der Frühzeit des Malers, vor dem Erlebnis des Krieges 19I4-I8, eine (wie Güse zeigte ${ }^{7}$ vitalistische, mit Nietzsches lebensbejahen-

${ }^{6}$ Heinrich Heine: Ludwig Börne - eine Denkschrift (1840), in: Sämtliche Schriften, hg. von Klaus Briegleb, Bd. 7, München 1976, I8. dem Vitalismus verwandte Emphase, ja tiefe Liebe zum Meer als lebenszeugendem Element, das immer in Bewegung ist, als heraklitisches Element. ${ }^{8}$

Im Sommer roos hielt sich Beckmann an der Nordsee, in Agger, Westjütland, im Sommer I907 am Vietzker-Strand an der Ostsee auf. Er malte 1905 u.a. "Große graue Wellen " und "Sonniges grünes Meer « (die 1982 in Bielefeld hingen), das beeindruckende Bild einer Mole, "Große Buhne" in starkem Querformat (80 x I60 cm, Museum der bildenden Künste, Leipzig, Abb. I) und das extreme Hochformat - ungewöhnlich für das Thema des Meeres - Nebelsonne (Slg. Schäfer); ein Brief

${ }^{7}$ Ernst G. Güse: Das Frühwerk Beckmanns, Frankfurt/ M./Bern 1977, vgl. meine Rezension in: Zeitschrift für Kunstgeschichte $4 \mathrm{I}, 1978,342 \mathrm{ff}$. 


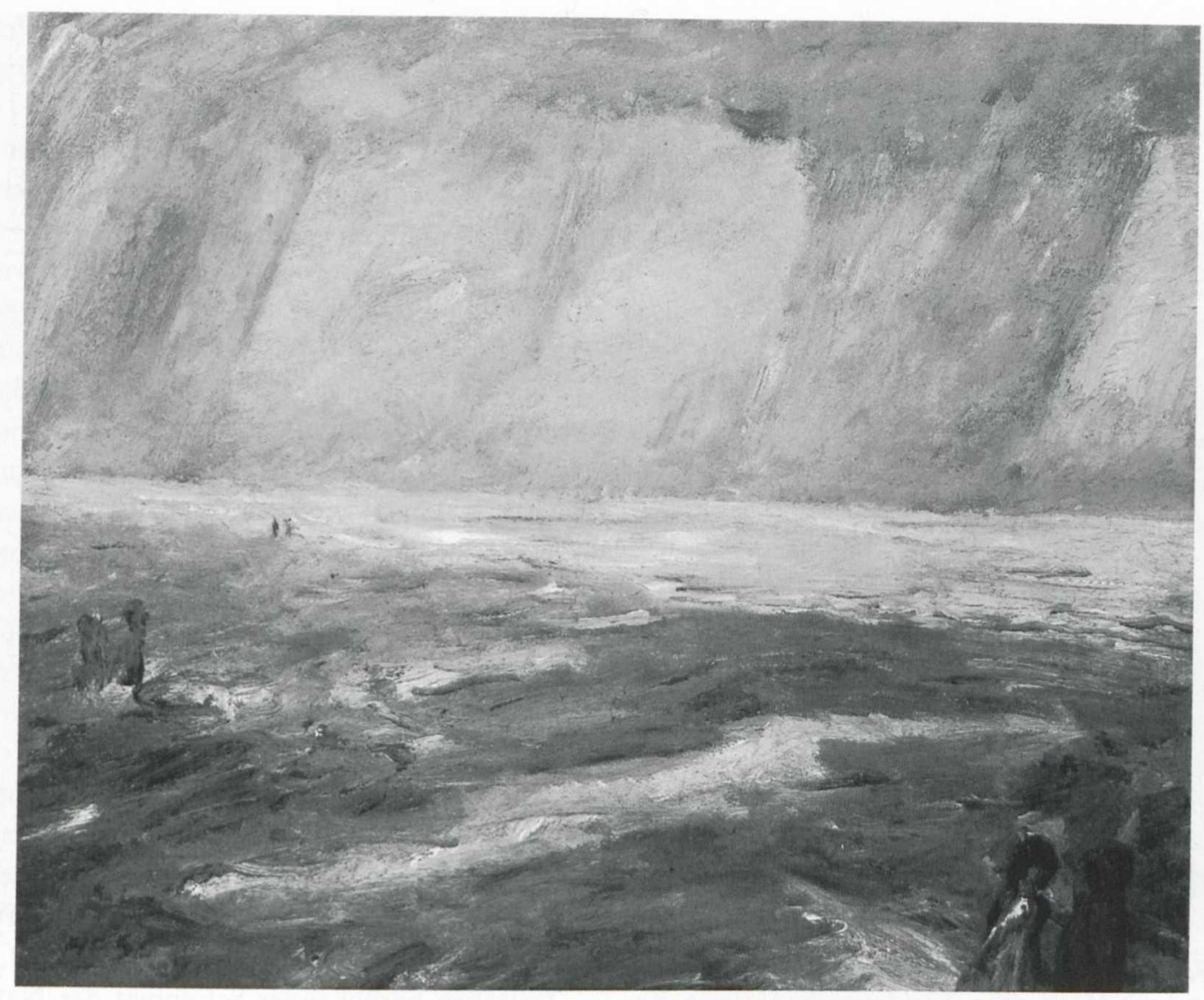

3. Max Beckmann: Abend am Meer, Wangerooge, I909, Regensburg, Museum Ostdeutsche Galerie

an den Malerfreund Cesar Kunwald, den sich Beckmann als Begleiter gewünscht hatte, berichtete: "Ich male hier Meer, Buhnen, Steine, Akte in der Sonne, Selbstporträts mit und ohne Meer, Korngarben etc. - alles direkt nach der Natur... «? Die Briefe legen Zeugnis ab über Cézanne und Van Gogh, seine malereigeschichtlichen Herolde, und deren Bewertung in Bezug auf Persönlichkeit, leidenschaftlichen Willen zur Gestaltung, Tiefe, Dramatik. Der junge Beckmann scheint Cézanne noch höher zu bewerten als den Holländer, was

${ }^{8}$ Dazu Georg Simmel: Schopenhauer und Nietzsche, Leipzig 1907; Walter Gebhard: Nietzsches Totalismus, Berlin/New York 1983, 7 off.

${ }^{9}$ Katalog Max Beckmann zum roo. Geburtstag, hg, von

Dieter Gleisberg, Museum der bildenden Künste Leip- sich aber später wandeln sollte. Die "Große Buhne« in Leipzig realisiert das Sujet, das der Dramatik van Goghs verwandt scheint, mittels Farbflekken in der koloristischen Technik Cézannes.

»Ich stehe jetzt nach vielerlei Stylproben endgültig zwischen Cézanne und van Gogh. Ich male jetzt wenn ich male mit aller Leidenschaft und Kraft, zu der ich überhaupt fähig bin ...« Darin, was Kunstschaffen für Beckmann bedeutete, das Bedürfnis zu gestalten und darin alle Intensität zu legen, teilte und verwirklichte er von Beginn an

zig 1984, no. 204; Klaus Gallwitz/U. M. Schneede/St. v. Wiese (Hg.), Max Beckmann-Briefe Bd. I: 1899-1925, München I993, 36-40. 
Nietzsches existentiell fundierten Kunstbegriff als Lebenssteigerung. ${ }^{10}$

Fortgeführt werden die Meeresbilder mit der Gruppe von 1907 an der Ostsee u. a. mit »Sonniges Meer" (Privatbesitz), "Sommertag am Meer" (Slg. Buchheim) und dem suggestiven "Seestück" (Museum St. Louis, Abb. 2)."I

Es ist hier nicht möglich, auf jeden kunstgeschichtlichen Aspekt und die Tradition der Gestaltungsweisen einzugehen, also die Impulse der Malerei Cézannes und solche der Raum-Auffassung van Goghs zu beschreiben. Auch Rückblicke auf die Küstenbild-Tradition von den Étretat-Bildern von Delacroix, Courbet und Monet bis Schuffenecker oder auf Werke Monets wie "Steilküste bei Pourville « 1882 (Museum Enschede) oder dessen Bilder auf Belle-Isle sind aus Platzgründen nicht möglich. ${ }^{12}$

Statt der prächtigen Schönheit der ununterbrochenen Veränderung des Meeres und des Flimmerns des Lichtes sucht Beckmann dann seit 1908/o9 einen dramatischen, ja deutlich bedrohlichen Zug, um die Gefährdungen zu zeigen: "Schiffbruch" von 1908 (Museum St. Louis) und "Abend am Meer" 1909 (Ostdeutsche Galerie, Regensburg). Angesichts dieser Werke hat Güse in der Untersuchung des Frühwerkes Beckmanns zu Recht die Tradition des Gedankens der «navigatio vitae» aufgegriffen, die Hüttinger in einem Aufsatz zum Bildmotiv des Schiffbruchs thematisiert hatte. ${ }^{13}$ Im Juni 1909 (und im August 1910) hielt sich der Maler auf Wangerooge auf, ${ }^{14}$ von den acht Gemälden von 1909 sind einige bis heute verschollen (»Durchbrechende Sonne am Meer" mit ge-

${ }^{10}$ Vgl. E. G. Güse (wie Anm. 7) 1977 und D. Schubert, Beckmann-Auferstehung und Erscheinung der Toten, Worms $1985, \mathrm{II} 3, \mathrm{I} 65$.

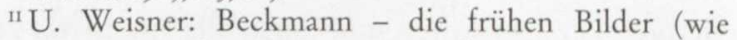
Anm. 4) 1982/83, no. 13, 14, 17 und 26; Kat. Beckmann Retrospektive, hg. von C. Schulz-Hoffmann, München 1984, No. 3-4; Katalog Beckmann Gemälde, hg. von D. Gleisberg/K. Gallwitz, Leipzig-Frankfurt/M. 1990/9I, no. 2; Katalog Max Beckmann-Meisterwerke, hg. von Karin v. Maur, Stuttgart 1994, no. 2.

${ }^{12}$ Arlette Sérullaz: Delacroix et la Normandie, Paris Musée Delacroix 1993/94. - Cat. Neo-Impressionisten, by Ellen W. Lee, Amsterdam 1988, No. 32 und 34. krümmtem Horizont; "Aufklärendes Wetter" u. a.). An seine Frau schreibt er im Juni 1909 einen dramatisch-phantastischen Brief:

"Heiße helle Luft. Der unendlich weite blendende Strand. Ganz weit hinten aus geschmolzen Erz die Sonne im Meer, darüber ein flimmernder staubig violett grau grün goldener Himmel, wie ein Schild, und in der Mitte das Haupt der Gorgo die Sonne. « Dann folgt eine visionäre Schlachtenszene am Strand, ein Reigen um das Standbild eines Gottes, den sie verhöhnen. »Ein schäumendes Meer mit blitzartig dahingleitenden Segeln, das Brüllen der Wogen hört sich an wie Erdbeben. Die Schatten am Horizont aber wachsen mit wahnsinniger Schnelligkeit... die Schatten werden schwärzer und immer undurchsichtiger. Trotzdem fühlt man den großen Raum ... Messerscharf und hart strahlt das Licht auf eine weite Unendlichkeit gelben hügeligen Sandes, eine lange schmale Gestalt geht langsam durch die Hügel ... seine Arme strecken sich ekastatisch begeistert in die Luft ... Ich liege auf einer Düne. Hinter mir höre ich das Rauschen des Meeres. Meine Augen sehen in den blauen Abgrund des Himmels ...

Zwischen berückender Schönheit der Naturereignisse und düsterer Drohung ihrer unberechenbaren Elemente für die Menschen changiert das Wangerooge-Bild »Abend am Meer « ${ }^{15}$ (50 x $60 \mathrm{~cm}$; Abb. 3, signiert »H B S L o9«), ganz aus Braunviolett und Rotocker aufgebaut. Kleine Menschenpaare sind der Weite, Tiefe und Bedrohlichkeit des Raumes konfrontiert. Der Himmel über dem veroneser-grünen Wasser wird mittels breiter Pinselstriche in Rotocker und Terra-Siena zu einer

${ }^{13}$ E. Hüttinger: Der Schiffbruch - Deutungen eines Bildmotivs, in: Beiträge zur Motivkunde des 19. Jahrhunderts, München I970, 21I-244; E. G. Güse (wie Anm. 7) I977, 36.

${ }^{14}$ Hans Kaiser: Die Kunst Max Beckmanns, Berlin 1913, 30-3r sah im Arbeiten mit dem Licht das Wesentlichste. Zur Wangerooge-Gruppe vgl. Erhard u. Barbara Göpel, Beckmann Katalog der Gemälde, 2 Bde. Bern 1976, no. Iro-I17; Beckmann- Briefe, Bd. I (wie Anm. 9) I993, 59-60 und 4I4; das Werk G. 116 befindet sich in Regensburg, Museum Ostdeutsche Galerie, Leihgabe des Landes Nordrhein-Westfalen. 


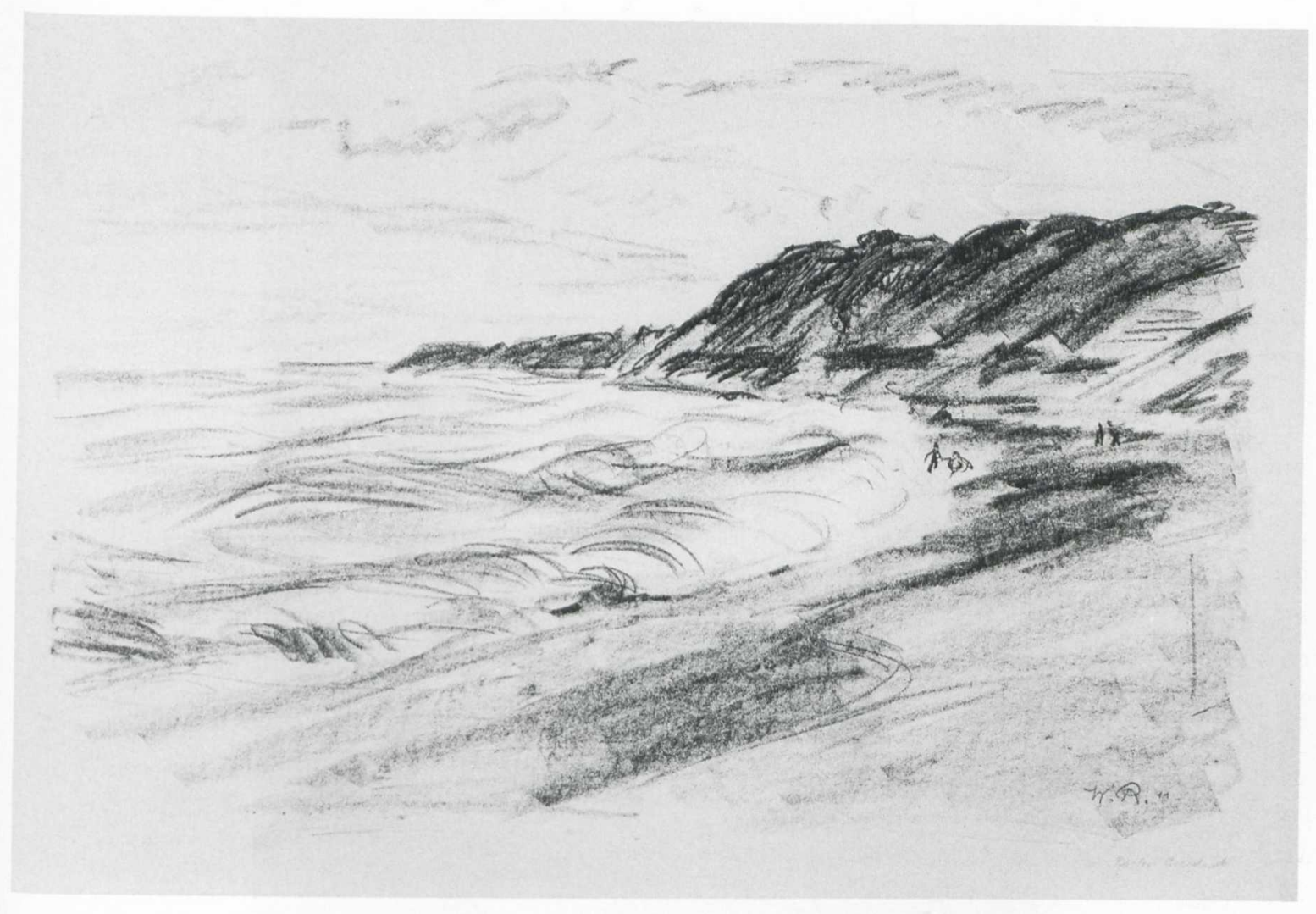

4. Waldemar Rösler: Meeresbucht, Kleinkuhren, I9I Lithographie, Privatbesitz

Wolkenwand transformiert, die sich gespenstisch nach rechts bewegt. Beckmann stellt nicht die heitere Schönheit der natürlichen Einheit von Wasser und Himmel im strahlenden Licht dar wie 1907 in "Sonniges Meer oder wie Vincent van Gogh im Juni 1888 mit seine Strandbildern in Saintes-Maries-de-la-Mer (Amsterdam), oder wie in der VanGogh-Nachfolge auch Beckmanns Freund Waldemar Rösler um 1912-I4 mit zahlreichen Strandund Meeresbildern in Graphik (Abb. 4) und Gemälden in einem betont koloristischen Malstil wie "Sommertag an der Ostsee" (Stuttgart, Staatsgalerie), "Bucht mit Badenden, Kleinkuhren«(Ost-

${ }^{15}$ Vgl. dazu C. Lenz: Bilder der Landschaft 1900-1916, in: Katalog Retrospektive (wie Anm. II) 1984, I17; - S. Rother: Beckmann als Landschaftsmaler (Diss. Köln), München 1990.

${ }^{16} \mathrm{Vgl}$. Katalog RösLer zum Ioo. Geburtstag, Regensburg deutsche Galerie, Regensburg). ${ }^{16}$ Der koloristische Stil Beckmanns, der das pedantisch zeichnerische Erfassen der Dinge vermeidet und damit in der Tradition des Kolorismus von Velázquez über Delacroix zu van Gogh und Cézanne steht, arbeitet zwar mit gleichen Prinzipien des Rapports der Farbflecken, darin vor 1914 ganz verwandt seinem Berliner Malerfreund Rösler. Aber hier sucht Beckmann mit der großen Wirkung der Farbklänge nicht die Pracht des Lebens zu feiern, nicht das Licht in der Abendstimmung am Meer, nicht nur die Weite des Raumes, sondern er thematisiert das Verschwinden des Menschen in den düsteren

1982, hg. von W. Timm, Text von D. Schubert; ferner D. Schubert: Erinnerung an Waldemar Rösler, in: Pantheon (München), Jg. XL, 1982, Heft 2, 160-16r; S. W. Laux: Waldemar Rösler (Diss. Univ. Heidelberg 1986), Worms 1989. 


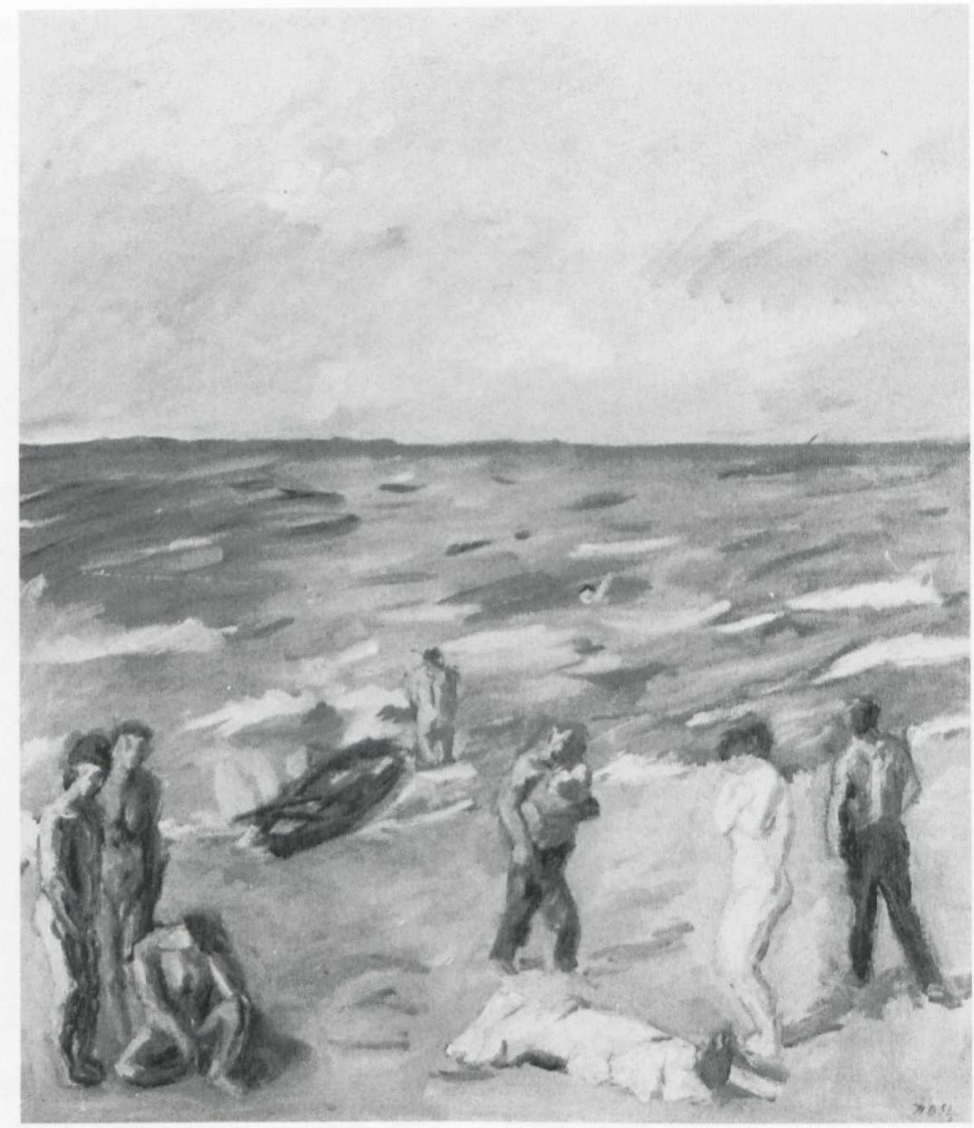

5. Max Beckmann: Schiffbruch, 1908, St. Louis, The Saint Louis Art Museum

Elementen. Hierin gibt es einen Bezug zu einem älteren englischen Maler, der sowohl für den modernen Kolorismus bedeutend war, als auch das Düstere der Natur am Meer gestaltete; es sind Bilder der Weymouth-Bay um I8I5 von Constable..$^{17}$ Die Leinwand »Schiffbruch $(80 \times 70 \mathrm{~cm}, \mathrm{Abb} .5)$ in Grau-Blau und in Ockertönen gehalten, zeigt einen Unfall an der Küste mit einer zerstreuten, hilflosen Menschengruppe um einen Ertrunkenen. Angeblich soll Beckmann einen ähnlichen Unfall bei Sylt beobachtet haben. Sachlichkeit und Authentizität machen sich bereits hier in Beckmanns Kunstwollen bemerkbar, - stärker dann nach 1918. Das gilt auch für die große, ehrgeizige

${ }_{17}^{17}$ Vgl. E. de Keyser: Das Abendland der Romantik 1789I850, Genf 1965, 128 Farbe.

${ }^{18} \mathrm{U}$. Weisner (Hg.): Beckmann - die frühen Bilder (wie Anm. II) 1982-83, No. 64; E. G. Güse (wie Anm. 7) 1977,
Leinwand, die er 1912-13 einem zeitgenössischen katastrophalen Ereignis widmete, - ähnlich wie der für Beckmann immer leitende Franzose Théodore Géricault dem Aussetzen von Schiffbrüchigen auf dem Floß der Staatsfregatte » Méduse « 1817 sein Hauptwerk "Das Floß der Medusa « I8I9 widmete (Paris, Louvre).

Bei Beckmann handelt es sich um die aus der Phantasie und Imagination gestaltete Katastrophe des Untergangs des Dampfers "Titanic" am is. April 1912; dabei kamen ca. I500 Menschen in den eisigen Fluten ums Leben. ${ }^{18}$ Beckmanns Vitalismus zufolge interessierte ihn besonders das Problem des Überlebens in den Booten, die Überfüllt-

35f.; Susanne Rother (wie Anm. 15) 1990; Karin von Maur, in: Katalog Meisterwerke (wie Anm. II) 1994, No. 3 und No. ro. 


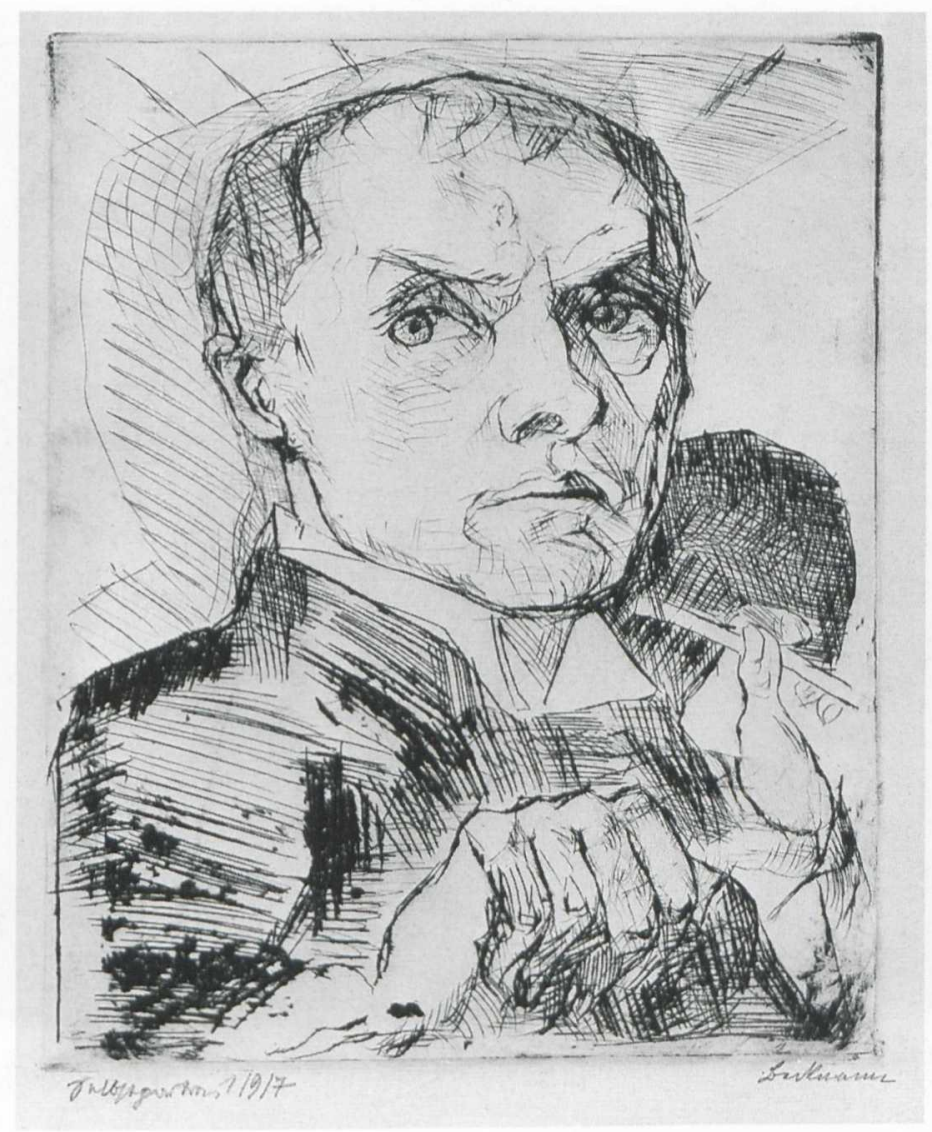

6. Max Beckmann: Selbstportrait 1917, Radierung

heit derselben und die verzweifelten Kämpfe zwischen den Lebenden und den Ertrinkenden. Denn an den überfüllten Booten werden von Insassen mit den Rudern Sich-Anklammernde brutal abgeschlagen.

Im kleineren "Schiffbruch «-Bild von 1908 hatte Beckmann keine Kampfszene eingebaut. Dort "herrschen die Ermattung und Verlorenheit" der Schiffbrüchigen vor (Güse, 36). Ob die große Leinwand mit Beckmanns subjektiver Interpretation der Titanic-Katastrophe so ausgelegt werden kann, in ihr sogar eine Art Vorahnung des Weltkrieges empfinden zu können (wie dies Reifenberg I949 wollte), ${ }^{19}$ möchte ich dahin gestellt sein lassen, halte es aber für Projektion. Sich auf solche

\footnotetext{
${ }^{19} \mathrm{~B}$. Reifenberg/W. Hausenstein: Max Beckmann, München 1949 .

${ }^{20}$ Beckmann - Briefe im Kriege (1916), München 1955,
}

Fragen einzulassen, würde hier zuweit führen; zumal einerseits der Ausbruch des Krieges I9I4 nicht ein natürlicher Orkan war, sondern von imperialistischen Vormacht- und Wirtschafts-Interessen ausgelöst, und andererseits die Frage, ob Beckmann sodann den Krieg, den er als Sanitäter erlebte, als eine Art »Naturereignis « begriff oder aber als ein sozial-politisches Ereignis, genauere Erörterungen nötig machen würde auf der Basis der Analyse seiner Briefe aus dem Krieg. ${ }^{20}$ Jedenfalls suchte er, die Erlebnisse im Kriegsgeschehen, »dieses wilde Leben, das entfesselt wurde« (10. 3. 1915) zeichnerisch festzuhalten (Abb. 6, Selbstportrait, Radierung 1917), unter Betonung der Tiefe, der Plastizität, des Vollen und Runden, des lebendig

3. Aufl. München 1984; D. Schubert: Beckmann - Auferstehung (wie Anm. 10) 1985; Karin von Maur, in: Katalog 1994 (wie Anm. II), $76 \mathrm{ff}$. 


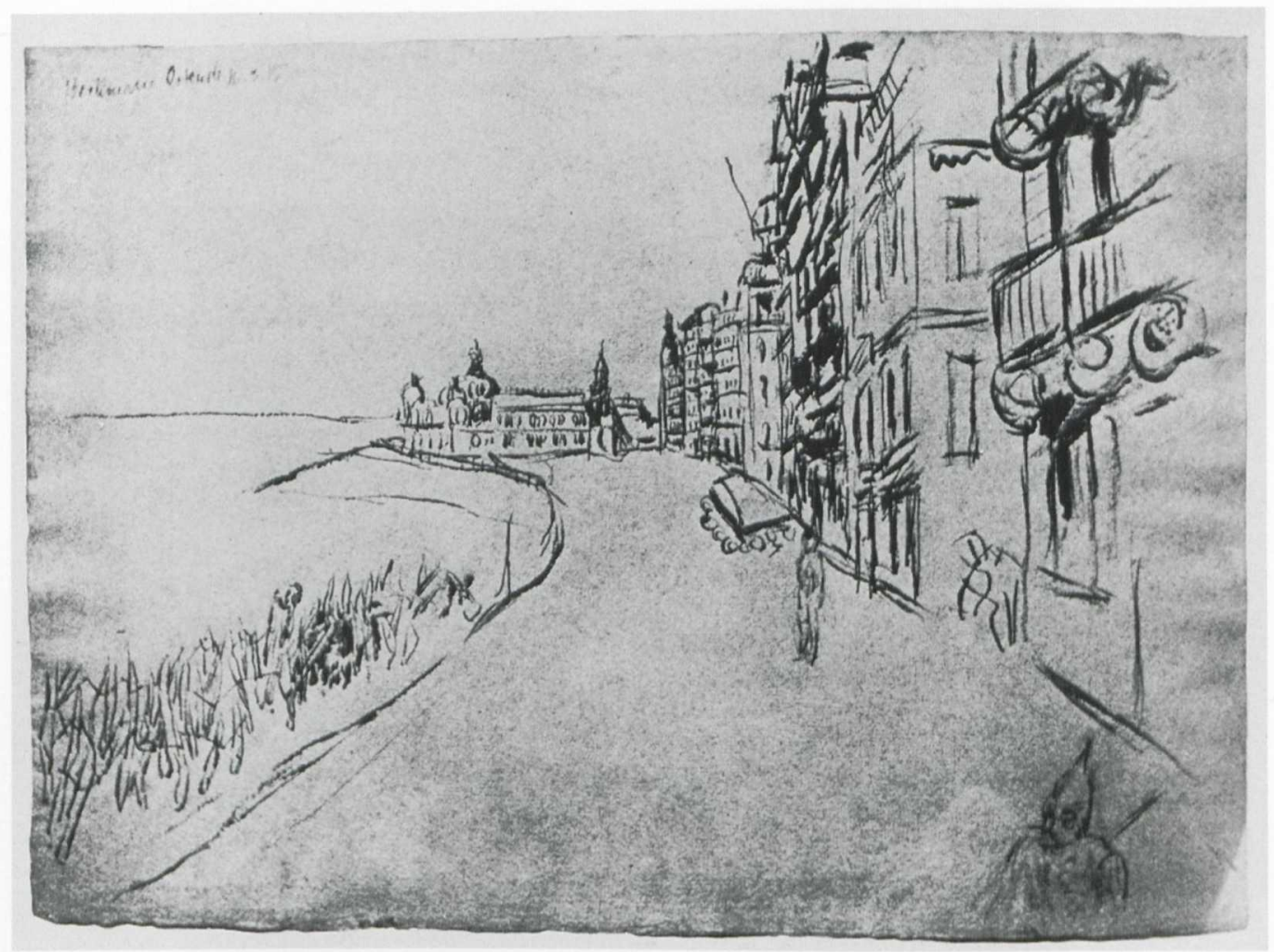

7. Max Beckmann: Strandpromenade Ostende, März 1915, Zeichnung

Pulsierenden (16.3. 1915). Und immer einerseits die Faszination am - selbst bedrohlichen - Erlebnis, die Lebens-Steigerung im Nietzsche'schen Sinne, andererseits auch die Angst und Depressionen. Er schreibt angesichts des Widersinns des Lebens im Kriege den programmatischen Satz: "Ich habe gezeichnet, das sichert einen gegen Tod und Gefahr * (3. Okt. I9I4). Er wolle alles Wesentliche ausdrükken, aber immer »im Kontakt mit der Sachlichkeit (8. 6. 1915). Am 2. März I9I5 aus Courtray an seine Frau Minna Tube: »Ich ... schwanke andauernd zwischen großer Freude über alles Neue, was ich sehe, zwischen Depression über den Verlust meiner Individualität und einem Gefühl tiefer Ironie über mich und ... die Welt.«

Beckmann liest in diesen Wochen wieder im " $\mathrm{Za}$ rathustra Nietzsches, das Neue Testament und von Jean Paul besonders den »Titan«. Er bekommt Visionen von Weltuntergängen und von Auferstehungen und schreibt über seine Ängste angesichts des »unendlichen Raumes«: »Diese grenzenlose Verlassenheit in der Ewigkeit. Dieses Alleinsein « (24. 5. 1915). Die Briefe Beckmanns aus dem Kriege gehören zu den tiefsten und wertvollsten Zeugnissen, die wir von Künstlern aus dem Ersten Weltkrieg besitzen.

Unbedingt mußte Beckmann das Meer sehen: am 16. 3. I9Is ergab es sich, daß ihn der Hauptmann und Direktor der Kunstgewerbeschule Charlottenburg mit nach Ostende nahm; ${ }^{21}$ der Maler fuhr im Auto an den Dünen und verglich den Wagen einem »fabelhaften Sturmvogel«; an seine Frau Minna schreibt er am gleichen Tage: »Und dann das Meer, meine alte Freundin, zu lange schon war ich nicht bei dir. Du wirbelnde Unendlichkeit mit deinem spitzenbesäten Kleide. Ach, wie schwoll

\footnotetext{
${ }^{21}$ Briefe im Kriege (wie Anm. 20) 1984, 27 "Prof. Th. «Kl. Gallwitz (Hg.) Beckmann Briefe Bd. I (wie Anm. 9), 107-108.
} 


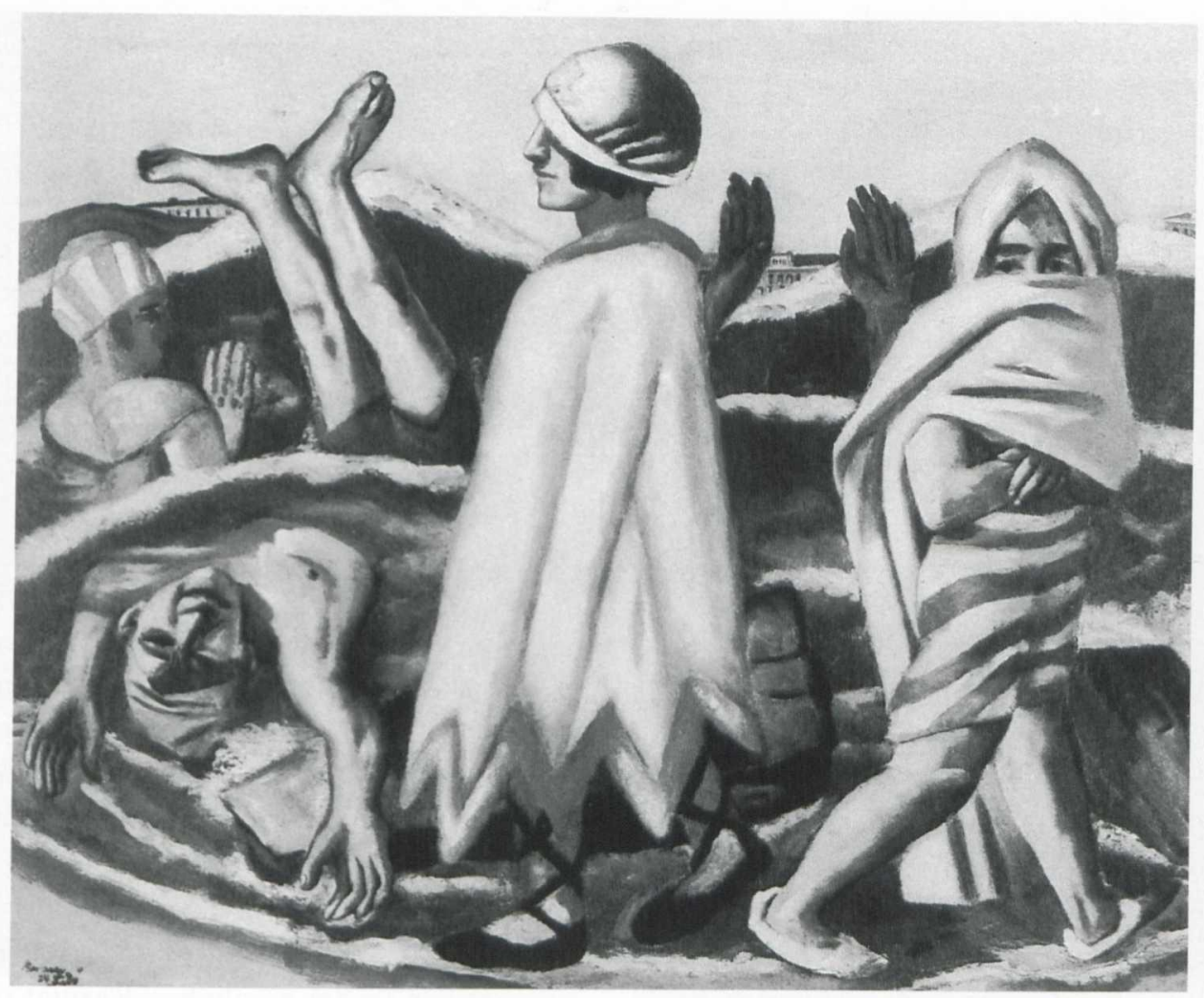

8. Max Beckmann: Lido, 1924, St. Louis, The Saint Louis Art Museum

mein Herz. Und diese Einsamkeit ... Wenn ich der Kaiser der Erde wäre, würde ich als mein höchstes Recht mir ausbitten, einen Monat im Jahr allein zu sein am Strand.«

Eine Tuschezeichnung von 37 x $52 \mathrm{~cm}$ (Privatbesitz) hielt den Eindruck von der Promenade Ostende fest, die im Brief als Ausgestorbenheit und traumhafte Zwielichtstimmung charakterisiert ist; "die kahlen Linien des entseelten Strandes ... die unheimliche Stille ... die fahlen spitzen Silhouetten von ein paar Soldaten, die langsam auf uns zukamen«; "alles Lebende war draußen. Jenseits«. Stephan von Wiese hat betont, ${ }^{22}$ daß sich Beckmanns Auffassung der Landschaft weg vom objektiven Realismus hin zum subjektiven Expressionismus zu wandeln beginnt, und zwar hier in

\footnotetext{
${ }^{22}$ Stephan von Wiese: Max Beckmanns zeichnerisches Werk, Düsseldorf 1978, no. 245.
}

Richtung Entfremdung und Unheimlichkeit, ja Entseelung, die durch »kahle Linien«, fahle spitze Formen und durch das Gestaltungsprinzip der Instabilität der Zeichnung anschaulich werden. Dazu gehört auch die geisterhafte Soldatengestalt rechts im Vordergrund (Abb. 7).

Nach dem Ende des Krieges, nach der November-Revolution und während der politisch-sozialen Kämpfe um 1919-192I widmete sich Beckmann primär der sozialen Lage der Menschen - statt subjektive Nabelschau zu machen oder sich artistischen Problemen zu widmen wie Kandinsky etwa; er suchte in der Serie "Die Hölle« von 1919 und in symbolisch überhöhten, verdichtenden Gemälden wie »Die Nacht«, die er ausdrücklich bezeichnete und somit betitelte »August I 8 - März 19 ", um dergestalt die reale Gewalt des sozialen Lebens dieser Monate zu gestalten, das Schicksal des Menschen in der Gewalt unter Menschen symbolisch darzustellen. ${ }^{23}$ 
Für Kasimir Edschmids "Schöpferische Konfession" in der r919 edierten Reihe "Tribüne der Kunst und Zeit« Bd. XIII (Berlin 1920) schreibt der Maler u. a. über sein neues Prinzip der »transzendenten Sachlichkeit ", über seinen Willen, »das zuckende Monstrum von Vitalität ... in glasklare scharfe Linien und Flächen einzusperren«. »Und gerade jetzt habe ich fast noch mehr als vor dem Kriege das Bedürfnis, unter den Menschen zu bleiben. In der Stadt. Gerade hier ist jetzt unser Platz. Wir müssen teilnehmen an dem ganzen Elend, das kommen wird. Unser Herz und unsere Nerven müssen wir preisgeben dem schaurigen Schmerzensgeschrei der armen, getäuschten Menschen. Gerade jetzt müssen wir uns den Menschen so nah wie möglich stellen ... (und) wir den Menschen ein Bild ihres Schicksals geben ... « ${ }^{24}$ Das Hauptwerk dieser Haltung war das Gemälde »Die Nacht» (Düsseldorf, Kunstslg. Nordrhein-Westfalen).

Es entstehen besonders die graphischen Zyklen "Die Hölle« 19I9, "Stadtnacht « 1920, »Jahrmarkt« I921 mit dem Selbstbildnis im "Circus Beckmann", die »Berliner Reise 1922. $^{25}$ Je etablierter Beckmann in den zoer Jahren jedoch wurde, umso mehr entfernte er sich vom sozialen Elend der Menschen, vor allem den Kriegsfolgen wie sie Grosz, Dix und Heartfield veranschaulichten, und ihrer Darstellung. Sein metaphysisches »ICH « beschäftigte ihn zunehmend; der Schwerpunkt seiner Lektüren verlagerte sich im übrigen weg von Nietzsches Vitalismus und Immanenzlehre hin zu Schopenhauers pessimistischer Weltsicht und dem Interesse an den Geheimlehren der Gnosis.

Zwischen 1922 und 1924 setzen wieder erneut die Natur- und Strand-Bilder in seinem Schaffen ein, wie beispielsweise in den Radierungen der "Mari-

${ }^{23}$ Carl Einstein, Die Kunst des 20. Jahrhunderts, Berlin I931, 182; C. Lenz: Beckmann und Italien, Frankfurt/M. 1976, 19; Kat.München Retrospektive (wie Anm. II) 1984, No. 19; K.Gallwitz (Hg.): Beckmann in Frankfurt, Frankfurt/M. 1984, S. 36; Katalog Max Beckmann in Frankfurt 1915-1933 - zum 100. Geburtstag, hg. von Kl. Gallwitz, Städel 1983/84, 78; Matthias Eberle: Beckmann - Die Nacht, Frankfurt/M. 1984 (Kunststück) gab eine merkwürdig fehlerhafte Deutung des Bildes, indem er in dem Mädchen rechts, das der Bandit hält und mit Gardinenseilen fesseln will, Beckmanns Sohn Peter be- ne", dem Hochformat einer "Küstenlandschaft mit Leuchtturm " und dem extremen Querformat "Strand", der Blick von den hohen Dünen aufs Meer mit einem auffällig gewölbten Horizont, ein Prinzip, das schon Vincent van Gogh im Sommer I888 am Mittelmeer in einer Federzeichnung realisiert hatte (Amsterdam, van Gogh Museum), die Beckmann freilich nicht kennen konnte bzw. brauchte. Der Stil dieser Kompositionen in seiner konstruktiven Klarheit hat nur partiell einen Anteil am Zeitgeist der Neuen Sachlichkeit; schließlich war Beckmann der »Erfinder « der Sachlichkeit lange vor der »Neuen Sachlichkeit«, was ihm durchaus bewußt war, wenn er im März 1926 an Wilhelm Hausenstein schreiben wird: »Die Gegenständlichkeit in einer neuen Kunstform wieder zur Debatte zu stellen, ist mein Anstoß gewesen ... Diesen Anstoß nun in einen neuen lebendigen Strom zu verwandeln, ist meine Lebensarbeit. Inzwischen ist dieses Prinzip vielfach aufgegriffen, leider des öfteren mißverstanden und banalisiert (worden) ...« Beckmanns Stil dieser Jahre ist unmittelbar an der sinnlichen Realität orientiert, jedoch scheinbar naiv, kleinteilig, aber voll Klarheit in der Konstruktion der bildnerischen $G e-$ stalt, ein Begriff, den er seit 1906 für sein Kunstwollen präferierte. Der Einfluss der naiven Malerei Henri Rousseaus stand hinter dieser neuen Gegenständlichkeit und sachlichen Dingbezeichnung in Gemälden wie »Nizza Frankfurt «, »Der eiserne Steg «, "Varieté«. Der Wandel in der bildnerischen Form - nicht in den Sujets - setzt gegen I924 mit größeren Flächen und der differenzierten Verwendung von Schwarz ein.

Besonders im Anschluß an einen Badeurlaub von Juli 1924 bei Pirano (südlich von Triest) entsteht

hauptete und in dem strangulierten Opfer im Zentrum den Maler, was völlig abwegig ist. Eine Zeichnung belegt, daß er ursprünglich bei dieser Figur an Karl Liebknecht dachte; vgl. dazu D. Schubert: Auferstehung (wie Anm. 10) 1985 , S. I23 und 177. Wie sich Beckmann selbst verstand, zeigen die Selbstporträts, besonders das von I921 als Clown mit der geöffneten Hand (Wuppertal). - Berechtigte Einwände gegen Interpretationen der "Nacht« jüngst bei Karl Arndt, Familie im Werk Max Beckmanns, in: Familienbindung als Schicksal, hg. von Th. Wolpers, Göttingen 1996, Anm. 33. 


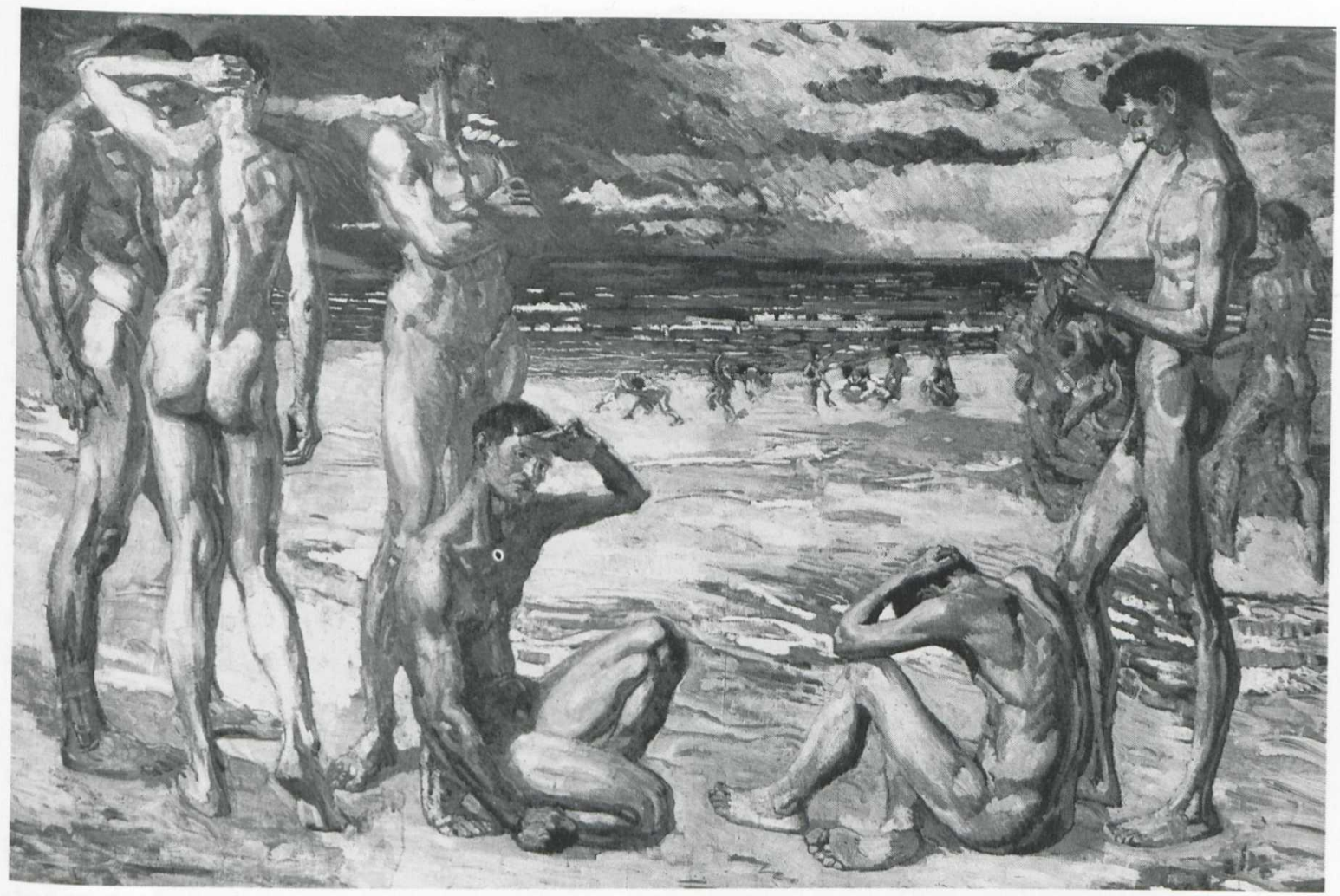

9. Max Beckmann: Jünglinge am Meer, 1905, Weimar, Kunstsammlungen

das Leinwand-Bild im Saint Louis Art Museum "Lido« (Abb. 8).

An den Händler I. B. Neumann berichtet ein Brief von den Erlebnissen am Meer. Der Maler will verstärkt die Schönheiten des »daseienden Lebens « gestalten; ${ }^{26}$ aber das Prinzip der Verfremdung, der Maskierung und der Groteskisierung wird jetzt jedenfalls den Sujets anverwandelt, um zwischen dem Sichtbaren und dem Unsichtbaren die Brücke zu bilden, bzw. eine höhere symbolhafte Ebene zu erreichen. Beckmanns Verwandlung der sichtbaren Realitäten in eine zirkushafte bzw. theaterhafte Sichtweise (das Leben = ein

${ }^{24}$ K. Edschmid (Hg.): Schöpferische Konfession (Tribüne der Kunst und Zeit 13), gedr. 1919, publ. Berlin 1920, 6I-67. Vgl. R. Spieler: Beckmann, Köln 1994, 38.

${ }^{25} \mathrm{Vgl}$. Alexander Dückers: Beckmann - Die Hölle 1919, Berlin I983. - James Hofmaier: Beckmann - Catalogue raisonné of his prints, 2 Bde., Bern 1990.

${ }^{26}$ Beckmann Briefe (wie Anm. 9) Bd. I, 1899-1925, 1993, 254.
"Welttheater", wie Jean Paul schrieb), die die Situationen von Karneval und jeglicher Maskierungen präferiert, wird auch in "Lido « deutlich: Es handelt sich letztlich um eine der vielen Variationen Beckmanns auf das menschlich-allzumenschliche Theater der Verhaltensweisen der Geschlechter, Beckmanns Hauptthema. ${ }^{27}$ Denn in den dunkelgrünen Wellen schwimmen etwas hilflos drei Männer, während am Strand zwei durch Badekleider und Tücher maskierte Frauen promenieren. Die Frauen, als die immer schön oder interessant sein wollenden, lustwandeln, sich zur Schau stellend, - während die immer aktiv sein

${ }^{27}$ C. Lenz, Mann und Frau im Werk von Beckmann, in: Städel-Jahrbuch 3, 1971, 213; D. Schubert, Beckmanns Liebespaar in "Messingstadt « von 1944 (Vortrag an der Universität München, Kunst-Hochschule Leipzig, 1995) im Druck. 
müssenden Männer sich im gefährlichen Spiel der Wogen des Lebens zugleich preisgeben, wie sie unterzugehen drohen. ${ }^{28}$

Die Unterschiede zu Beckmanns erstem großen Werk, "Jünglinge am Meer" von igos (Abb. 9; Schloßmuseum Weimar, 1906 in Weimar beim Künstlerbund ausgestellt, erhielt den Villa-Romana-Preis durch Graf Keßlers Hilfe), ${ }^{29}$ eine Strandszene mit sechs Jünglingen im Vordergrund, komponiert entsprechend der vitalistischen Lebenskultur der Nietzsche-Impulse nach 1900, könnten nicht stärker gedacht werden: 1905 der nackte Mensch in seiner subjektiven Existenz-Gebärde und jungen Leibsprache eingebettet in eine intakte Natur; ${ }^{30}$ dagegen 1924 der mondäne Bade-Ort "Lido« mit den sozial überformten Gestalten und ihren maskierten Rollenspielen, "ambivalent zwischen zwei Daseinsformen« (Lenz).

Nach Rückkehr aus Italien schrieb Beckmann am 9. 8. 1924 an Neumann: "Ich war I4 Tage in Italien am adriatischen Meer und habe dort wundervolle Dinge gesehen, an deren Verwirklichung ich jetzt herangehen will. Ich male Portraits, Stilleben, Landschaften, Visionen von Städten, die aus dem Meer auftauchen, schöne Frauen und groteske Scheusäler. Badende Menschen und weibliche Akte - kurz ein Leben. Ein einfach daseiendes Leben. Ohne Gedanken oder Ideen. Erfüllt von Farben und Formen aus der Natur und aus mir selber - So schön wie möglich. « ${ }^{3}$

Tatsächlich folgen vor den großen mythologischen Rätselbildern und vor den mystischen WeltTheatern der Triptychen in den 2oer Jahren ausgezeichnete Bildnisse, Landschaften, weibliche Akte, Figuren wie die "Zigeunerin" von 1928

${ }^{28}$ C. Lenz, (wie Anm. 23), 1976, 21 sah auch drei Männer (abweichend von Carla Schulz-Hoffmann, im Katalog München 1984, no. 40); Karin v. Maur im Kat. Stuttgart 1994 (wie Anm. II), 90 sah in der rechten Frau mit den dunklen Augen einen Mann, was ich nicht erkennen kann. Werner Timm, in: "Thalatta - das Strandbild, Regensburg 1989, 29f.

${ }^{29}$ Eine Quelle sind die immer noch unveröffentlichten frühen Tagebücher Harry Graf Keßlers, einem der Begründer des Deutschen Künstlerbundes, Tagebücher 1902-1906 (Marbach, Dt. Lit. Archiv); Keßler hat zwischen dem I. Juni und dem II. Juni r906 u. a. zu Beck-
(Hamburg, Kunsthalle), Stilleben und eine Reihe von Meer- bzw. Strand-Gemälden.

Im Gegensatz zur kleinteiligen Malweise und quasi-naiven Dingbezeichnung der frühen zoer Jahre, unter Einfluß des Zöllners Rousseau, wandelt sich jedoch Beckmanns Malstil um die Mitte der zoer Jahre zu breiteren Formationen, auf farbigen Untermalungen (z. B. rötlich) aufgetragene breite Flächen, die Plastizität suchen, die das Weiß und das Schwarz als die Pole des Lebensdaseins bewußt betonen. Dieser Stilwandel gipfelt in dem 1927 vollendeten Selbstporträt im Smoking (Cambridge/Mass., Busch-Reisinger Museum), das im Jahr des Textes "Der Künstler im Staat" (mit der Idee der Vergottung des Menschen) ${ }^{32}$ den Regisseur des »Welttheaters « und des Zirkus Beckmann in herausfordernder Pose zwischen Dunkel und Hell wie einen Magier des Daseins zeigt.

Im Frühsommer 1928 hielt sich Beckmann mehrere Wochen am Meer bei Scheveningen auf. Es entstanden meisterhafte Strandbilder, die synthetisch Tiefenraum in der Fläche suggerieren: auf rötlicher Untermalung, in fast quadratischem Format, beinahe nur aus Rottönen aufgebaut, der Blick um "Fünf Uhr früh « aufs Meer, mit den Buchstaben aus der Zigaretten-Werbung »Roocht Miss Blanche« (Abb. Io; Staatsgalerie moderner Kunst, München) und das steile Hochformat "Abend am Meer" mit untergehender Sonne (Privatbesitz R. L. Feigen, USA). ${ }^{33}$

Beckmann greift ein Kompositionsprinzip auf, das bereits Pierre Bonnard in seinem Spätwerk I919 verwendet hatte, nämlich den Blick über einen Vordergrund, der dem Raum des Malers zugehört, über einen Zwischenraum von Balustraden oder

mann notiert: »Weimar-Eröffnung der KünstlerbundAusstellung ... Das Interessanteste ... das Bild eines ganz jungen Künstlers ... Max Beckmann Nackte Jungen am Strande, signorellisch und viel Qualitäten von Courbet und Cézanne, aber doch von starker Eigenheit im Rhythmus der Akzente und in der Tonalität, die eine bemerkeswerte Einheit hat. Mich Beckmann vorgestellt und ihm gratuliert. « Am 3. Juni 1906 traf Keßler Beckmann in Berlin: »... Ich fragte ihn, ob er gerne nach Florenz ginge. Er sagte, gerade das brauche er. Mit ihm zu Meier-Graefe hinaus gefahren, diesen und Schröder mitgenommen und in Beckmanns Atelier wo 


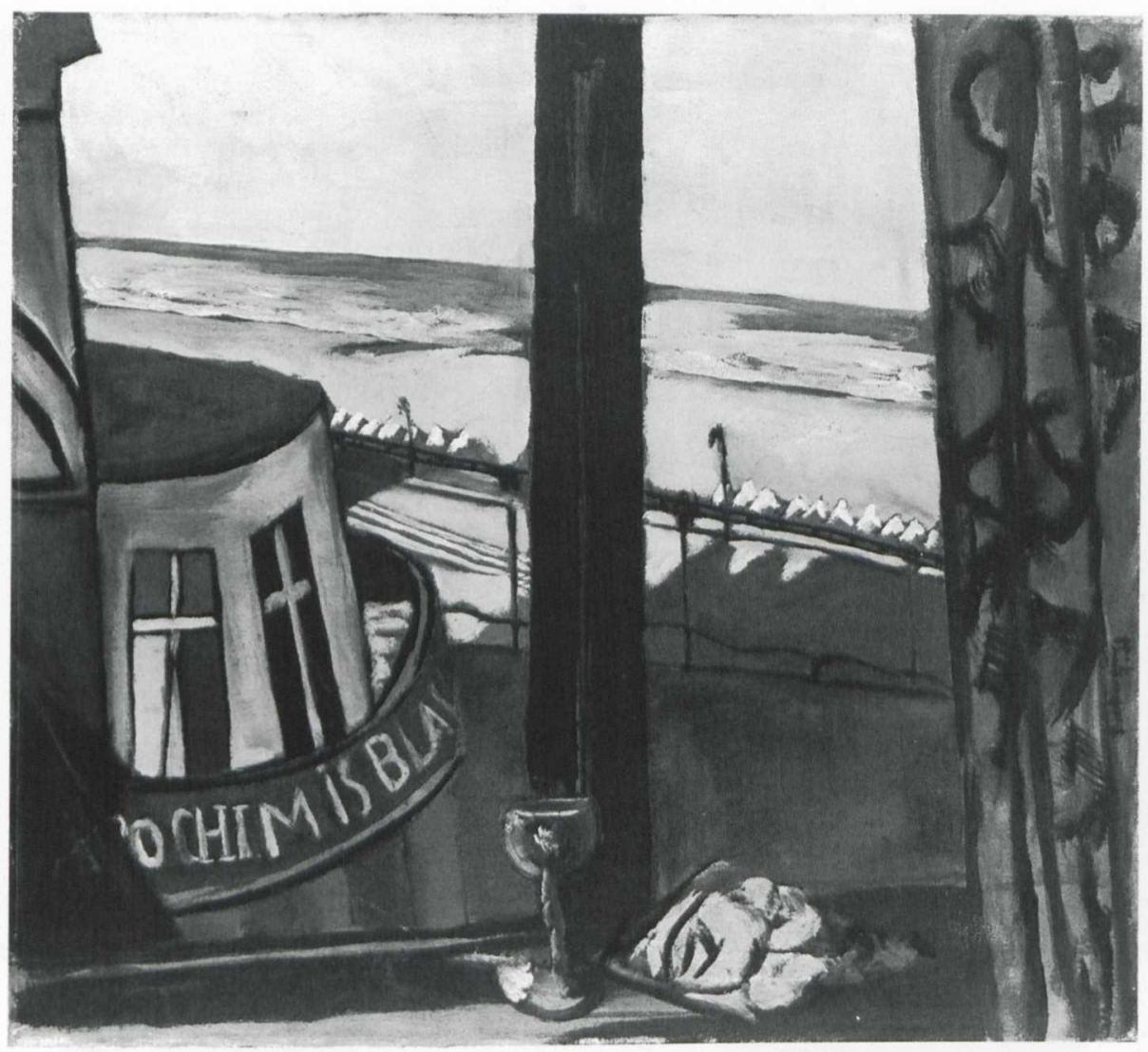

IO. Max Beckmann: Scheveningen, fünf Uhr früh (rot), 1928, München, Staatsgalerie moderner Kunst

Balkongeländern hinaus auf die See und den Himmel. Wie zwei Figuren begegnen sich die blauen Abendwolken über dem gleichfarbigen Meer, und die helle Lichtzone des Himmels wird auf der Nässe des Strandes widergespiegelt. Das Runde und Tiefe erscheint vollkommen auf der Fläche des Gemäldes, und doch suggeriert die Komposi-

er uns eine angefangene große Kreuzigung und eine Anzahl von Studien zeigte, die meine Achtung vor seinem Talent noch erhöhten. Er ist durch und durch Maler, wie es die Deutschen selten sind ....

Zu Kessler vgl. G. Schuster, Harry Graf Kessler - Tagebuch eines Weltmannes, eine Ausstellung, Marbach 1988; zum frühen Beckmann vgl. Hans Kinkel, Max Beckmann - Leben in Berlin Tagebuch 1908/o9, München 1966.

${ }^{30} \mathrm{~B}$. B. Buenger: Beckmanns Beginning - "Junge Männer am Meer «, in: Pantheon, 1983, Heft II, 134-I43; Schubert: Auferstehung (Anm. 20) 1985, I0; - R. Spieler 1994, I4. tion völlig das, was Beckmann immer zentrales Anliegen war: den Raum. Dies gelingt u.a. durch die Aufnahme von Gegenständen aus mehreren Tiefenplänen in die Komposition, besonders durch Vorhang oder Balkonrahmung im Vordergrund. Diese extremen Überschneidungen im gewählten Bildausschnitt, die zu einem Staccato der

${ }^{31}$ Briefe Bd. I, 1993 (wie Anm. 9 und 26); - ferner C. Lenz 1976 (wie Anm. 28), 20; - Karin von Maur 1994 (wie Anm. II) 90.

${ }^{32}$ Max Beckmann: Der Künstler im Staat, publiziert in: Europäische Revue, III, Juli 1928, Heft 4, 288f. - vgl. Beckmann - die Realität der Träume in den Bildern, hg. v. R. Pillep, Leipzig 1984, $116 f$.

${ }_{33}$ Katalog Max Beckmann - Sammlung Lackner, Bremen-Luzern 1967/68, no. I; Katalog Retrospektive (wie Anm. II) München 1984 , no. 51 . 


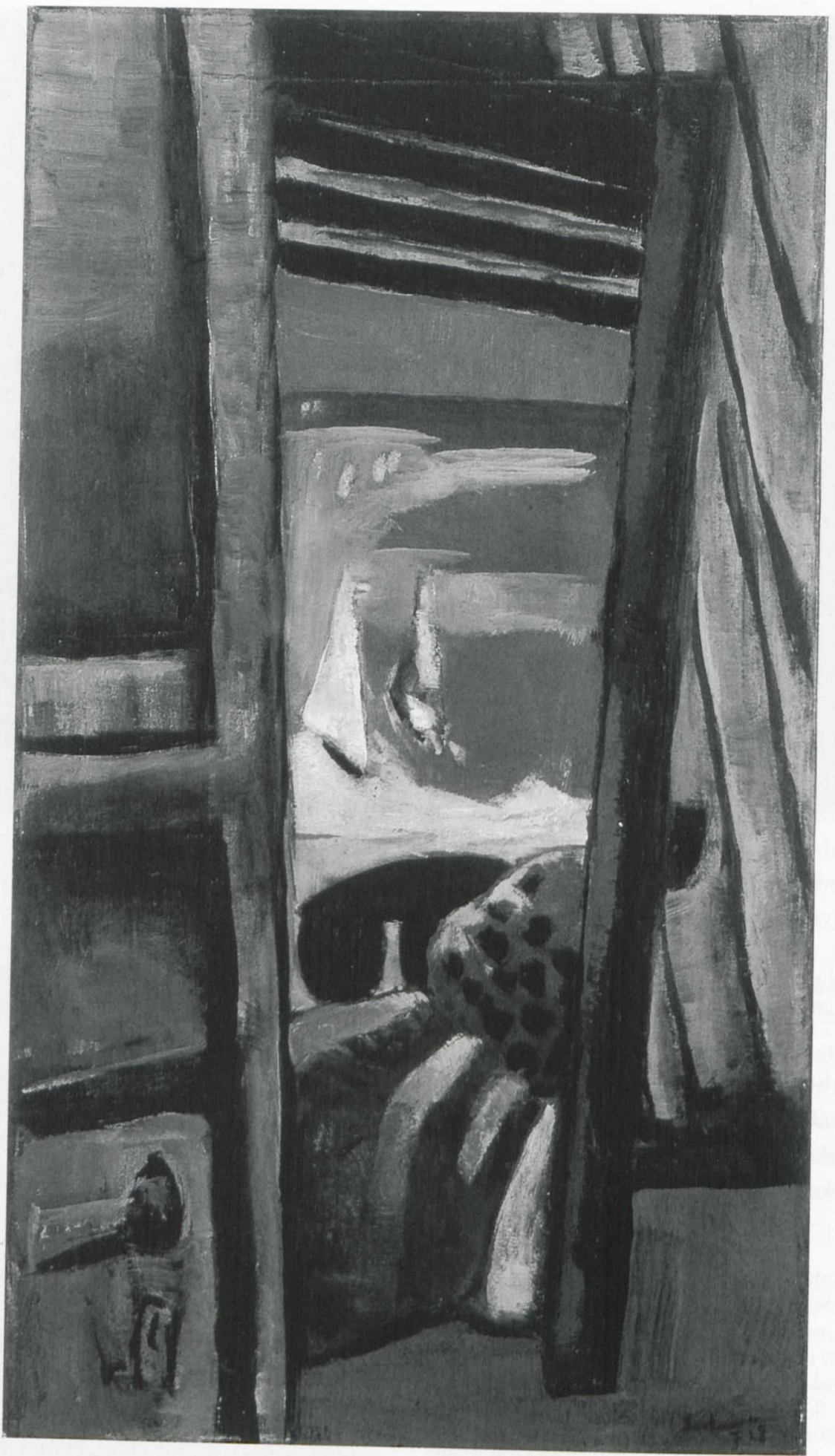

II. Max Beckmann: Blick aufs Meer, Scheveningen (rot grau blau) r 928 ; ehemals Museum Köln, 1937 beschlagnahmt, Köln, Museum Ludwig 


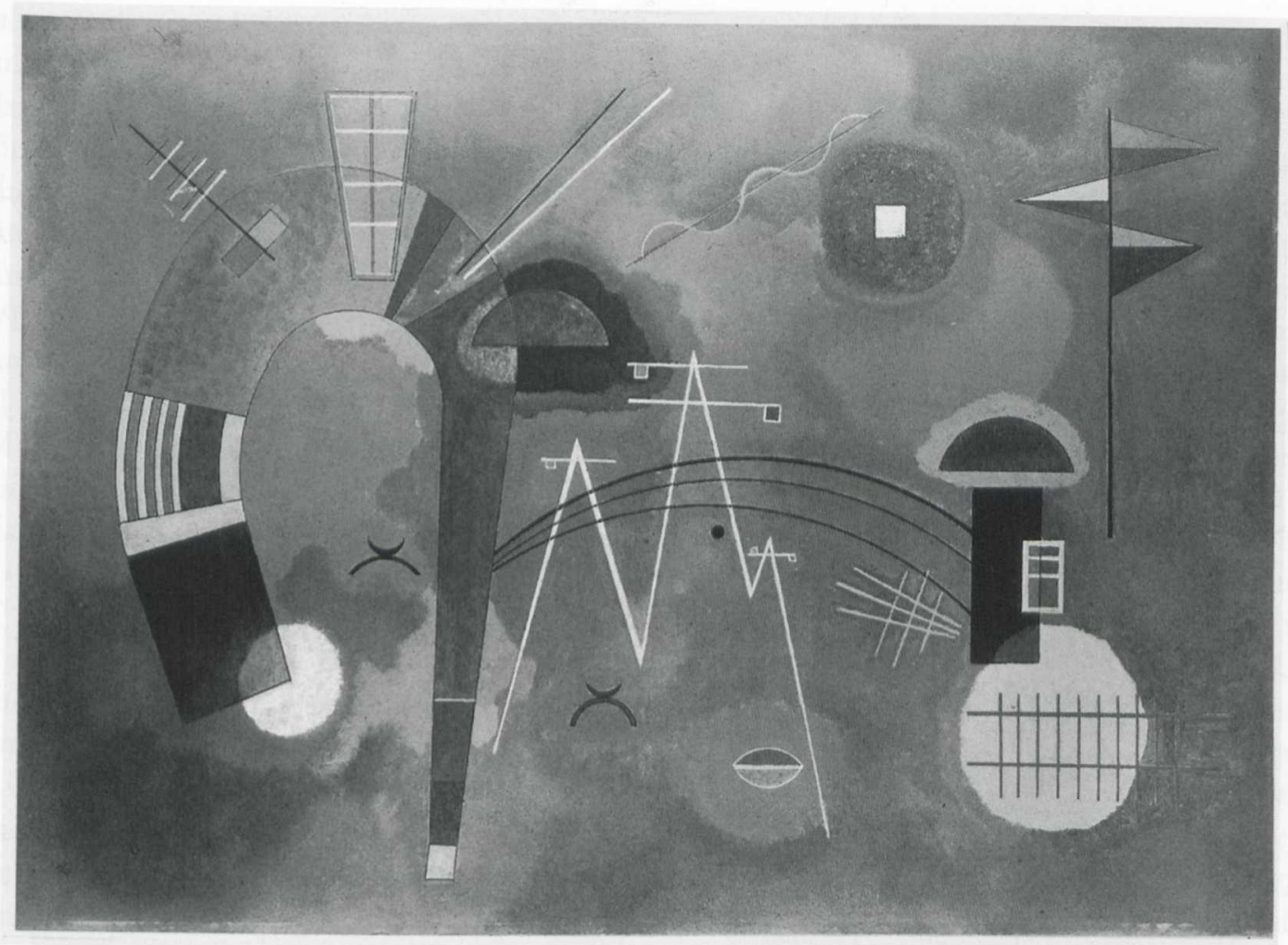

I2. Wassily Kandinsky: Rund und spitz, 1930, Gemälde, Mannheim, Kunsthalle

Tiefenraum-Wahrnehmung beim Betrachter führen (»Perspektivbeschleunigung «),34 hat Beckmann in seinen Gemälden von 1928 auf die Spitze getrieben: in dem steilen Hochformat "Blick auf's Meer (rot grau blau) (ehem. Museum Köln, 1937 "entartet«, Abb. II, Museum Ludwig, Köln) öffnet sich quasi die Türe in einen unendlichen Raum, der mittels Blau und Weiß und die kleiner werdenden Boote erlebbar wird. ${ }^{35}$

Die »Badekabine (grün) (Staatsgalerie moderner Kunst, München), die zu dem roten Bild als Pendant verstanden werden kann, demonstriert ebenfalls in der Verschachtelung der Raumbezüge

${ }^{34}$ Vgl. dazu C. Schulz-Mons, Beckmanns Landschaftsbilder, in: Katalog Max Beckmann - Kunsthalle Köln 1984, 89.

${ }^{35}$ Im Jahre 1929 von der Stadt Köln erworben, 1937 beschlagnahmt (Göpel WV 291); aus Privatbesitz versteigert 24. Auktion Villa Grisebach, Berlin 1992, no. 42, heute wieder Köln, Museum Ludwig. Vergleiche zu der Scheveningen-Gruppe auch Katalog Beckmann in dichter, flächiger Konfiguration der Dinge im Jahr 1928, daß die gegenstandslose Malerei, die etwa in Wassily Kandinskys Bildern »Ruhe und »Milder Vorgang « von 1928 oder »Rund und spitz « von 1930 (Mannheim, Kunsthalle, Abb. I2) ${ }^{36}$ - auf einem Höhepunkt war, eine existentielle und ästhetische Vereinseitigung ist. Denn Beckmann gibt in seinen Gemälden ästhetische Sensationen wie die gegenstandslose Malerei, aber darüber hinaus wesentlich mehr: eine Gestaltung und Deutung von sichtbarer und unsichtbarer Wirklichkeit in Werken von gleichermaßen suggestiven Formen und Farben, meisterhafte Flächenkom-

Frankfurt 1915-1933 (wie Anm. 23), 1983/84, no. 62-67, "Abend am Meer « Farbe dort 147.

${ }^{36}$ Dazu P. A. Riedl, Kandinsky, Reinbek 1983, II4 und dagegen kritisch Carl Einstein, Die Kunst des 20. Jahrhunderts (1926), 3. Aufl. Berlin 1931, 200-208 "Malerei: ein Mittel geistiger Isolierung gegen die Welt« - »eine Flucht vor den Dingen, um ein isoliertes, mediales Training zu ermöglichen .... 
positionen in der Synthese mit einem dreifachen Raum-Erlebnis (wie er es immer wieder forderte, besonders 1938 in seiner Londoner Rede). ${ }^{37}$ Beckmanns Kunst kann als synthetisch im höchsten Sinne verstanden werden; er verfügte über die Fähigkeit der psychischen Kontrolle und Bewußtmachung seiner Visionen, handwerklich über »tektonische Kräfte « und die »metamorphotische Kraft « (Carl Einstein), ${ }^{38}$ die Visionen in allgemein gültige Bilder zu überführen.

Aber er steht andererseits auch im Gegensatz zum extremen Gegenpol der Abstrakten, also zu den Naturalisten, d. h. zu den Malern der sog. "Neuen Sachlichkeit «; im Unterschied zu diesen klebt er nicht an der fotografistischen Wiedergabe der Dinge in platter, "phantasieloser Gegenständlichkeit" oder "mittelmäßigen Codakfilmen in trübem Rousseauaufguß « (wie er selbst 1926 an W. Hausenstein schrieb) ${ }^{39}$. Beckmann sucht die $\gg \mathrm{Me}^{-}$ taphysik in der Gegenständlichkeit", - wie seine Vorbilder Grünewald, Bruegel, Hogarth, Goya, auf die er sich berief. "Raum - Raum - und nochmals Raum - die unendliche Gottheit, die uns umgibt und in der wir selber sind. Dies suche ich zu gestalten durch Malerei ", sagte er in seiner Londoner Rede im Juli 1938. „Wir brauchen die Übersetzung des dreifachen Raums der Welt der Objekte in den zweifachen der Bildfläche. Wird die Bildfläche nur mit einem zweifachen Raumerlebnis gefüllt, so entsteht Kunstgewerbe oder Ornament « (s. Anm. 37).

Auch später 1948 , in den "Briefen an eine Malerin«, lehnte Beckmann eine »gedankenlose Imita-

37 „Wir brauchen die Übersetzung des Dreifachen Raumes der Welt der Objekte in den Zweifachen der Bildfläche. Wird die Bildfläche nur mit einem zweifachen Raumerlebnis gefüllt, so entsteht Kunstgewerbe oder Ornament. Sicher kann man sich auch daran ergötzen. Mir selber ist es langweilig ... Höhe - Breite - Tiefe in die zweidimensionale Fläche zu verwandeln, ist mir stärkstes Zaubererlebnis, aus dem mir eine Ahnung jener vierten Dimension entsteht, die ich mit meiner ganzen Seele suche«(London 21. Juli 1938).

${ }^{38} \mathrm{Vgl}$. hierfür insbesondere Carl Einstein (wie Anm. 36) 1926, 3. Aufl. 1931, 21I und 184: Beckmann versuchte zweifellos etwas wie eine Summe der Modernen zu erzwingen ....

${ }^{39}$ Brief Beckmanns vom 12. 3. 1926 an Wilhelm Hausen- tion der Natur « ab; vielmehr müsse die Gestaltung jene Veränderungen enthalten, die erst die Kunst, die echte Abstraktion, ausmacht. Die Grenzlinie zur bloßen Formkunst (Farbe und Form auf der Fläche) darf jedoch andererseits nicht überschritten werden, sonst entsteht neben der "gedankenlosen Imitation" als dem einen Pol eine "sterile Abstraktion (Kunstgewerbe) " als der andere Pol. ${ }^{\circ}$ Diese programmatische Position, die Beckmanns Bedeutung innerhalb der Moderne des 20. Jahrhunderts begründet, die bereits I9I2 in seiner Kontroverse mit Franz Marc im $» P A N \ll$ aufschien, ${ }^{4 I}$ wird an vielen seiner Gemälde aus den zoer Jahren deutlich wirksam, auch an der »Badekabine" von 1928, - die den Blick von der schwarzen Türe rechts über den hellen Fenster-Ausblick, die grünen Bauten am Strand und die Wogen hinaus auf eine Gruppe kleinster Menschen im Meer und einen Himmelstreifen gestaltet (Abb. 13), - eine Komposition von größter Dichte und Qualität. Signifikant ist dieses Bild auch wegen des Buches auf dem besonnten Fenster: es handelt sich um eines der Lieblingsbücher des Malers, um Jean Pauls "Titan" von $\mathrm{I}_{\mathrm{O}} \mathrm{O}-\mathrm{O} 4$. Auf die zahlreichen Aspekte der gedanklichen Impulse von Jean Paul auf Beckmann kann hier aber nicht eingegangen werden. ${ }^{42}$

Da ohnehin hier nicht alle Strandgemälde und Graphiken Beckmanns bis I950 behandelt werden können, habe ich mich auf die Zeit bis zur Emigration im Sommer 1937 beschränkt, weil dieses $\mathrm{Da}$ tum einen Einschnitt in Beckmanns Leben bedeutete. Aber auch innerhalb dieses Zeitraums können nicht alle Strandbilder erörtert werden. Ich er-

stein, siehe in D. Schubert: Otto Dix , Reinbek 1980, 3. verb. Auflage r991, 82 ; nicht bei R. Pillep (wie Anm. 32) 1984; Beckmann Briefe, hg. von K. Gallwitz u. a., Band II, bearbeitet von Stephan von Wiese, München/Zürich 1994, 34 .

$4^{\circ}$ Max Beckmann, Sichtbares und Unsichtbares, Stuttgart 1965, 28 und 42. - Dies scheint mir im Grunde ein Widerspruch zu Kandinskys unhaltbarer These von I9I2 (Über die Formfrage), die »Große Realistik « sei gleich der »Großen Abstraktion«; beide bezeichnen ja lediglich die extremen Pole, die Beckmann ablehnte und die bereits Jean Paul in der "Vorschule der Ästhetik " 1804 als "poetische Materialisten " und als "poetische Nibilisten $\approx$ beschrieb. 


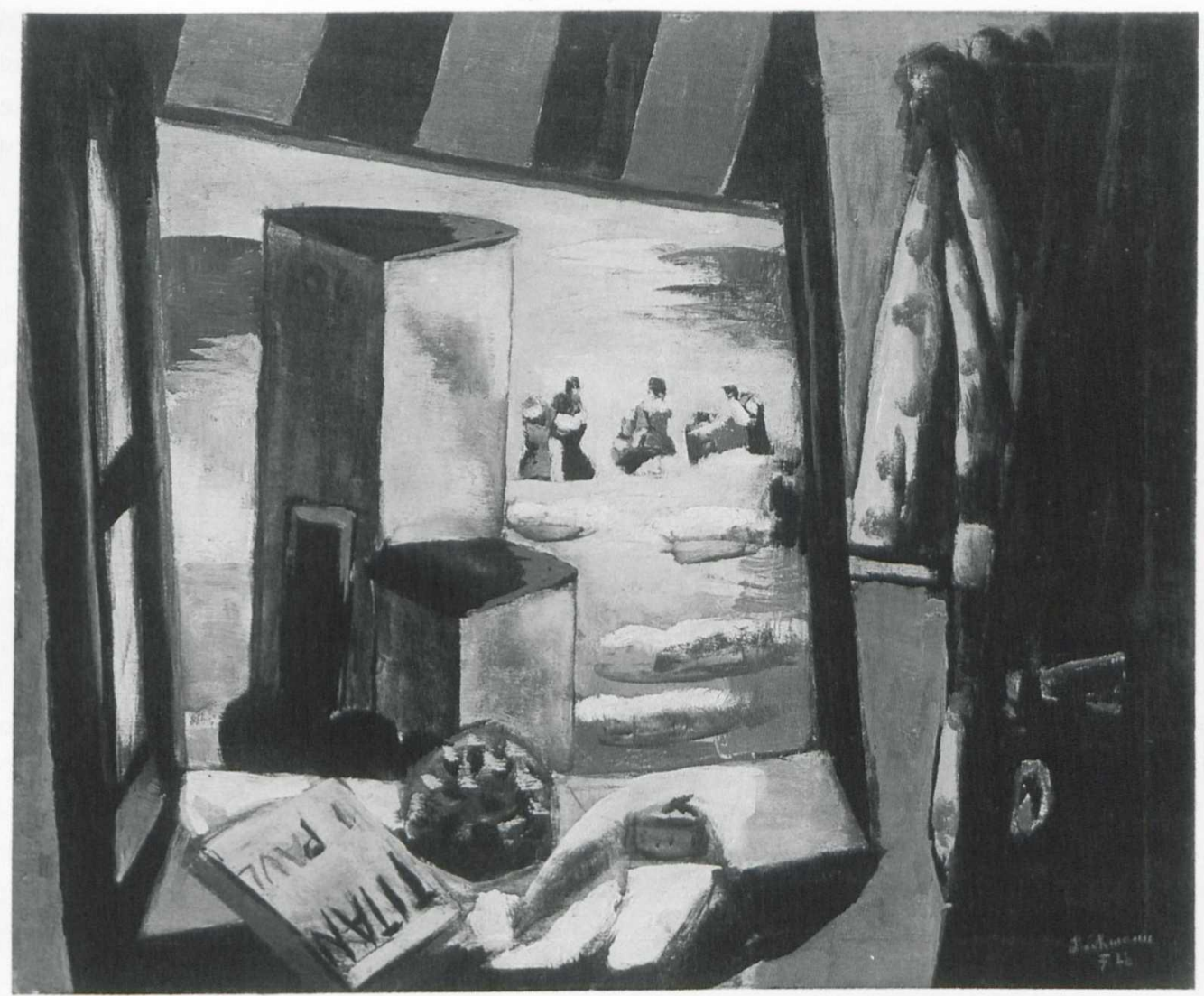

I3. Max Beckmann: Badekabine, Scheveningen (grün), 1928, München, Staatsgalerie moderner Kunst

wähne kurz - um dann auf zwei wichtigere Gemälde der zoer Jahre zu kommen - hier noch lediglich eine Strand-Landschaft von 1934, »Blick auf Zaandvoort « 43 (1986 bei Christie’s versteigert), ein Beispiel für die zwischen Hell und Dunkel changierende Palette Beckmanns, für die suggestive

${ }^{41}$ Kat. Die frühen Bilder (wie Anm. 4), Bielefeld 1982, $32 \mathrm{ff}$; D. Schubert, Die Beckmann-Marc-Kontroverse, ebenda $175-187$; derselbe, "Sachlichkeit « versus »innerer Klang « - die Beckmann-Marc-Kontroverse von 19I2, in: Expressionismus und Kulturkrise, hg. von Bernd Hüppauf, Heidelberg 1983, 207-244.

${ }^{42}$ Einen Beginn zu Beckmann und Jean Paul hinsichtlich der Symbole für Tod, Liebe, Unsterblichkeit hat Joan M. Wolk gesetzt (Katalog Beckmann, Frankfurt/M. I983/84, 5I-57; D. Schubert, Auferstehung, 1985, 109); es wäre aber ein Irrtum zu meinen, Beckmann habe den "Titan « erst kurz vor dem Bilde »Badekabine « gelesen. Bereits die Briefe aus dem Kriege bezeugen die Kenntnis der Werke Jean Pauls: am 28. 5. I9Is erwähnt der Ma-
Raum-Sog-Wirkung seiner Werke und speziell für die Wölbung der Horizonte in seinen Meerbildern. Ferner ein Figurenbild von 1933, das die Strand-Thematik anhand dreier Figuren aufgriff: der »kleine Wels« (Musée National Paris), eine Variation auf die Geschlechter-Thematik: der

ler die »Flegeljahre«. Die "Rede des toten Christus vom Weltgebäude herab, daß kein Gott sei« von 1789 , dann 1796 im "Siebenkäs «, beeinflußte u. a. Beckmanns zweite »Auferstehung «, die Erscheinung der Toten. Und den "Titan« kannte er bereits lange vor dem Krieg, denn er schreibt am 7. 6. 1915 an seine Frau, während er Kämpfe erlebte und Weltuntergangs-Visionen hatte: »- eine wüste Quälerei ist das Leben, ich wollte, ich säße auf dem Mars (und) läse den Titan«. 1928 kann also mit der wiederholten Lektüre dieses Buches gerechnet werden.

43 Catalogue Christie's, London 23. Juni 1986, Abb. 49 Öl auf Lw. 40,5 x 99 cm groß. Im Werk-Verzeichnis von E. u. B. Göpel (wie Anm.14), 1976, no. 399. 
kniende, an einen Clown erinnernde Mann reicht den Fisch - hier Sexualsymbol - zwei unterschiedlich typisierten Frauen entgegen, von denen die eine gelassen und überlegen, die andere jedoch ängstlich und moralisierend abweisend reagiert.

An der Typologie der Frau war Beckmann durchgängig interessiert, ja er entwickelt diese geradezu in Graphiken und Gemälden wie »Frauenbad « (1919, 1922), »Akrobaten«-Triptychon von 1939, dem »Grossen Frauenbild « 1935, dem Liebespaar in »Messingstadt « von $1944 / 45,{ }^{44}$ den »Fischerinnen«(1948), »Columbine«(1950) und dem unvollendeten Triptychon »Amazonen - Ballettprobe . Auch in seinem eigenen Lebensplan stand der Maler natürlich zwischen verschiedenen Frauen. Besonders die uns heute wenig bekannte Naila (Dr. Hildegard Melms, 1922 promoviert in Staatsökonomie), ${ }^{45}$ eine starke Persönlichkeit, die er nicht gewann oder die ihr Leben nicht mit Beckmann teilen wollte, beschäftigte ihn als Typus, eine Frau mit einer expansiven Augenstellung, mit tizianrotem Haar und offenbar besonderer erotischer Strahlung. Immer wieder taucht Naila in den Verbildlichungen von Beckmanns Phantasie auf: in den Graphiken von 1923 "Tamerlan " links vorn im Profil (der Mann an ihrer Seite ist Max B.?), in "Der Vorhang hebt sich«, in Radierungen zum Märchen »Fanferlieschen « von Brentano, in der Radierung »Traum/Totenklage« und in mehreren Bildnissen der Graphik 1923 und als Ölbild 1934 (ehem. Slg. Buchheim, Privatbesitz Schweiz).

Die zauberhafteste Darstellung Nailas, was bislang noch nicht gesehen wurde, findet sich $\mathrm{m}$. E. im Hamburger Gemälde »Odysseus und Kalypso « von 1943, das den Maler selbst mit der Geliebten, die er verlassen möchte, in den mythischen Rollen zeigt. Nicht nur die Trennung, auch den

\footnotetext{
${ }_{44} \mathrm{Vgl}$. meinen Vortrag 1995 »Beckmanns Liebespaar in der Messingstadt « (wie Anm. 27).

${ }^{45} \mathrm{Zu}$ Naila vgl. D. Gleisberg/Eugen Blume, Katalog der Grafik, in: Kat. Leipzig I884, no. 151, I6I; Karin von Maur/Beate Bender, Biographie Beckmanns, in Kat. Meisterwerke 1994, 217; Briefe Bd. I, bearbeitet von Uwe M. Schneede, 1993, 493. Ich danke Stephan von Wiese für mündliche Auskünfte.
}

Absturz der Liebenden hat Beckmann gefühlt. Er stellt ihn über dem Meer dar unter Betonung des Nackten, also der leiblichen Liebe, als einen Ritt auf Tieren mit sexueller Bedeutung, und zwar im Gemälde »Reise auf Fischen « (1934, Abb. I4, Staatsgalerie Stuttgart), ein Bild, das von seinem motivgeschichtlichen Impuls durch Max Klingers Radierung "Verführung " das heraklitische Element des Meerwassers übernahm, ein rätselhaftes Bild, das im CEuvre Beckmanns durch einen Holzstock aus den 2oer Jahren miterklärt wird. Denn dort halten die stürzenden Liebenden im Kosmos ihre Totenmasken in den Händen; Beckmann ist gut erkennbar in der Männerfigur. Im Gemälde von 1934 verallgemeinert der Maler die Identität der oben hockenden Frau und des in den Abgrund über dem Meer blickenden Mannes ins Unbestimmte, aber er gibt ihnen deutlich die schwarzen Masken des anderen in die Hand: die Frau (Naila?) hält Beckmanns Maske, der Mann hält eine Maske mit dem Profil Nailas. Demnach wäre dieser Sturz der Liebenden über der schwarzen Form als Teil des Meeres, das im hellblauen Teil ein Segelboot in freier Fahrt als Lebensalternative zeigt, eine Vision des Malers zum möglichen Schicksal von ihm und seiner (um 1923) Geliebten Naila, und nicht - wie Karin von Maur schrieb ${ }^{46}$ - die Erkenntnis, »angesichts der zunehmenden Bedrohung durch den Naziterror (mit seiner Frau Mathilde) schicksalhaft aneinander gekettet « zu sein. Der Terror der Nazis setzte außerdem später ein; Beckmann fühlte sich $1933 / 34$ noch nicht bedroht, er war weder jüdischer Herkunft noch Sozialist oder Kommunist. Gestaltete Beckmann in "Reise auf Fischen « das Meer in seinen zwei Seiten - als rettendes Element und als schwarzen Abgrund zugleich, so gab er im Triptychon "Abfahrt « kurz zuvor, begonnen schon I932, das strahlende Blau des Meeres als

${ }^{46}$ Auf die signifikante Kontroverse um das Gemälde »Reise auf Fischen « zwischen C. Lenz und K. von Maur kann hier nicht weiter eingegangen werden, siehe Karin von Maur, Beckmann - Reise auf dem Fisch, Berlin 1992 (Patr. 58 Kulturstiftung der Länder) und im Kat. Meisterwerke 1994, II2-II4; Christian Lenz, in Neue Zürcher Zeitung 5./6. März 1994 und die Erwiderung von K. von Maur in: Neue Zürcher Zeitung I6. 


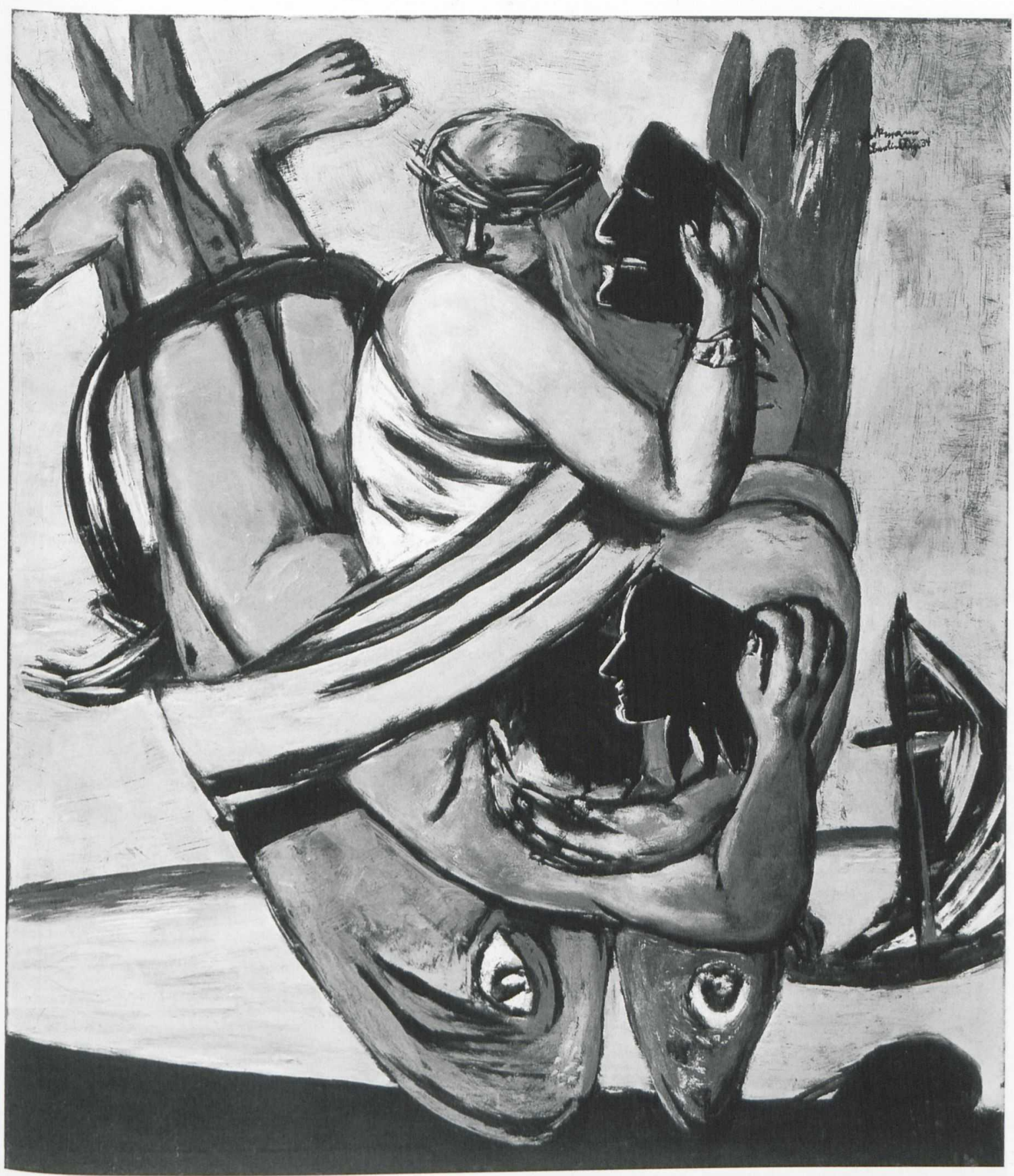

14. Max Beckmann: Reise auf Fischen, 1934, Stuttgart, Staatsgalerie

April 1994, 35. Die Datierung des Holzstocks "Reise auf dem Fisch" um I950 ist sicher nicht haltbar. Sieht Lenz richtig, daß auf dem rechten Flügel von "Abfahrt « die Frau mit dunkelrotem Haar und der Lampe wiederum Naila ist, so wäre die Wunde der von ihr getragenen
Männerfigur ein Hinweis darauf, daß Naila Beckmann verließ, verletzte? Vgl. schon D. Gleisberg/D. Blume, Katalog Leipzig 1984, 178 zu der Radierung "Der Vorhang hebt sich « 1923 . 
Folie für die Reise der mythischen Familie in die Freiheit von Zeit und Raum.

Der Maler entschied sich zwischen den wirklichen Frauen seines Lebens - aus welchen Gründen immer - 1925 für Mathilde Kaulbach, die er im September 1925 heiratet, der er am 3. Juli 1925 in einem aufschlußreichen Brief ihre Rolle im gemeinsam $\mathrm{zu}$ lebenden »herrlichen Theater « zugeteilt hatte: »Macht über mich wirst Du stets nur durch Deine Schwäche, niemals durch Deine Stärke haben! «

Nach dem Beginn der Diktatur der Nazis 1933 wird Max Beckmann ebenso wie andere Künstler im März-April von seinem Lehramt an der Kunstgewerbeschule/Städel-Schule in Frankfurt/M. entlassen (zum 15. April). ${ }^{47}$

Der Kampf gegen alle mißliebige Kunst (der »Novemberverbrecher «) wird eröffnet: nicht nur gegen die Abstrakten wie Kandinsky oder Molzahn und die Surrealisten und Expressionisten, vielmehr besonders gilt der Haß der NS-Funktionäre auf allen »Kulturbolschewismus « vor allem den sozialkritischen Realisten und kritischen Veristen (wie Dix, Schlichter, Grosz, Heartfield, Voll). Die ersten Ausstellungen der sogenannten "Entarteten « Kunst - so in Dresden - werden als "Spiegelbilder des Verfalls « bereits im Sommer 1933 organisiert, also Jahre vor der Münchner Schau I937, und zwar in Mannheim von April-Juni als »Kulturbolschewistische Bilder«, ebenso in Karlsruhe im April 1933 als »Regierungskunst «, in Stuttgart die Schau "Novembergeist im Dienste der Zersetzung «, und vom 23. September an in Dresden die Schau »Entartete Kunst« mit dem "Schützengraben « von Dix, mit Volls Skulpturen und Grosz' Bild "Abenteurer « im Zentrum. ${ }^{48}$

${ }^{47} \mathrm{Kl}$. Gallwitz (Hg.), Max Beckmann in Frankfurt 19151933, Frankfurt/M. 1983, 348; Vgl. dazu jüngst M. und B. Schwarz, Dix und Beckmann, Mainz 1996; das Buch operiert von einem arroganten Standpunkt herab, bleibt aber oft oberflächlich. Die unterschiedliche Wirkung der Ideen Nietzsches auf beide Maler spart man der Bequemlichkeit halber aus.

${ }^{48}$ Hildegard Brenner, Die Kunstpolitik des Nationalsozialismus, Reinbek 1963, 37-38; D. Schubert, Politische Metaphorik bei Otto Dix 1933-1937 (Vortrag Berlin, Nov. 1988), in: Kunst und Kunstkritik der zoer Jahre, hg. von M. Rüger, Dresden 1989, erweitert in: OTTO DIX - Katalog zum ioo. Geburtstag, hg. von W. Her-
Beckmann verhielt sich still; er versucht in Berlin unterzutauchen. Zwar wird eine Beckmann-Ausstellung in Erfurt 1933 unterbunden, auch der Beckmann-Saal in der Berliner National-Galerie nach der Entlassung des Direktors Ludwig Justi aufgelöst, doch kann Beckmann im Gegensatz zu Künstlern mit Ausstellungsverbot noch bis 1936 seine Werke zeigen, u. a. im Deutschen Künstlerbund, dessen Mitglied er war. ${ }^{49}$ Und er scheint abgewartet zu haben.

Erst als zahlreiche (nämlich 38) seiner Werke ab 19. Juli 1937 in Münchens Polit-Schau »Entartete Kunst « hängen, entschließt er sich dazu, Deutschland zu verlassen, geht jedoch nicht nach Paris, wo er in den zoer Jahren eine Wohnung und r93I eine größere Ausstellung hatte, sondern siedelt nach Amsterdam über. Dort meinte der Maler später, er könne das Rauschen des Meeres hören (Vortrag London 1938).

Ein auf roter Untermalung entstandenes Werk äußerster Dramatik bildet die "Kaimaner im Sturm " (Abb. I5, heute im Städel) $)^{50}$ aus dem Jahr 1936. Auf Format 40 x $80 \mathrm{~cm}$ gibt Beckmann einen Brandungsausschnitt unter dunklem Nachthimmel, hohe drohende Wogen, die gegen die rotbraune Mauer schlagen; diese wird - wie eine $\mathrm{Pa}$ raphrase auf Paul Klees Malerei - anthropomorphisiert, denn die zwei schwarzen Ringe-Augen formen beinahe das Antlitz eines steinernen Kopfes. Die Symbolik bleibt jedoch unbestimmt, denn die Entschlüsselung der metaphorischen Struktur hängt wohl in erster Linie vom Selbstverständnis des Betrachters ab. Ich möchte offen lassen, ob Beckmann tatsächlich die Bedrohlichkeit der Jahre $1934-36 \mathrm{zu}$ einem Überbild des menschlichen

zogenrath, Stuttgart-Berlin 199I/92, 273ff.; M. von Lüttichau, in: Die Kunststadt München 1937, München 1987, 83ff. und I2off.; derselbe und C. Zuschlag, in: Degenerate Art, hg. von S. Barron, Los Angeles I99I, deutsche Ausgabe München 1992, $45 \mathrm{ff}$. und 99 f. die Vorläufer-Ausstellungen.

${ }^{49}$ Annegret Janda, Das Schicksal einer Sammlung, Berlin-Ost 1986; Katalog Deutscher Künstlerbund 34. Ausstellung Bonn 1986 » 936 Verbotene Bilder «, 98; A. Janda/J. Grabowski. Kunst in Deutschland r905-1937- Die verlorene Sammlung der Nationalgalerie Berlin, Berlin 1992, 8I-83.

${ }^{50}$ Göpel (wie Anm. I4) 1976, no. 432. 


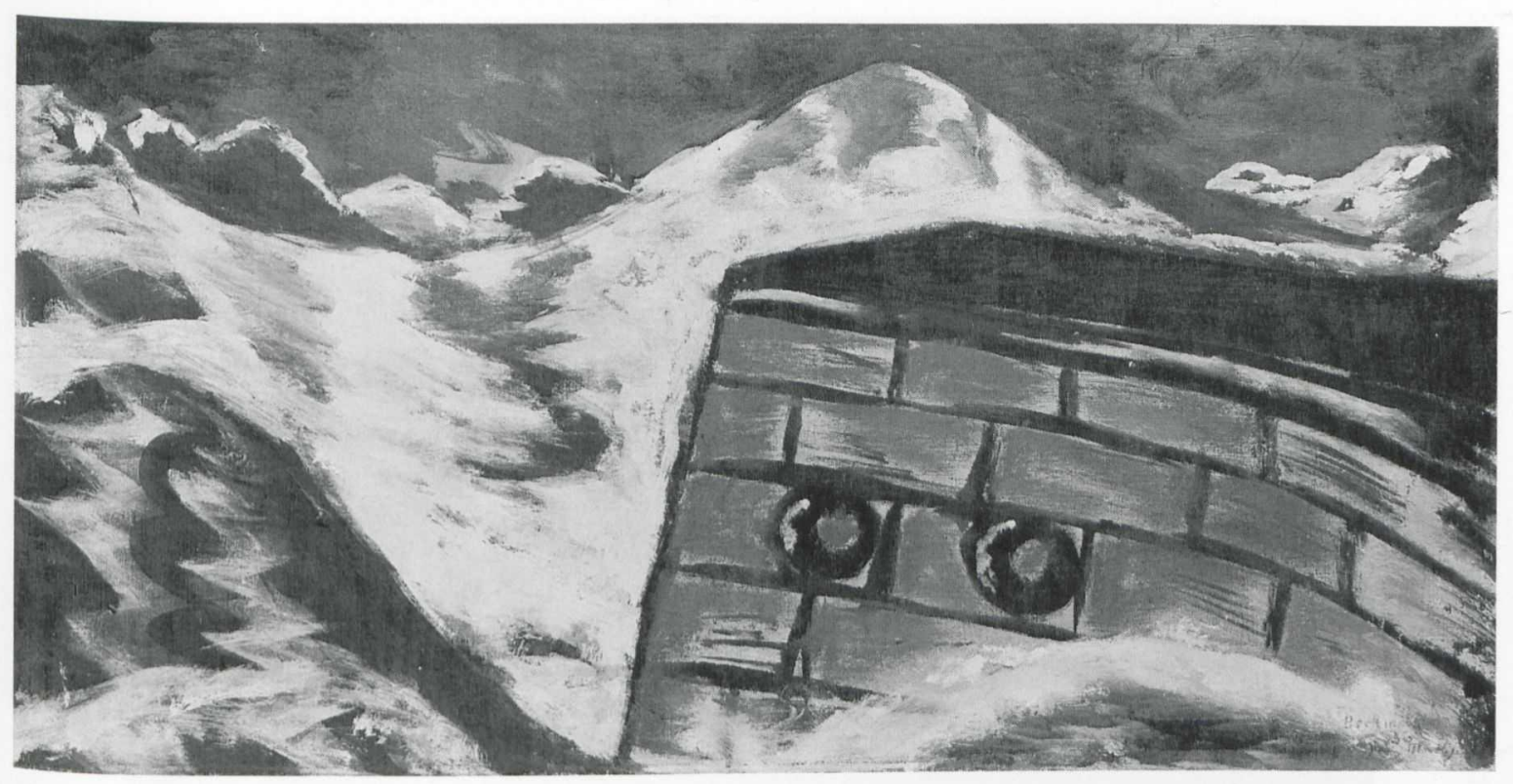

I5. Max Beckmann: Kaimauer im Sturm, 1936, Frankfurt/Main, Städelsches Kunstinstitut

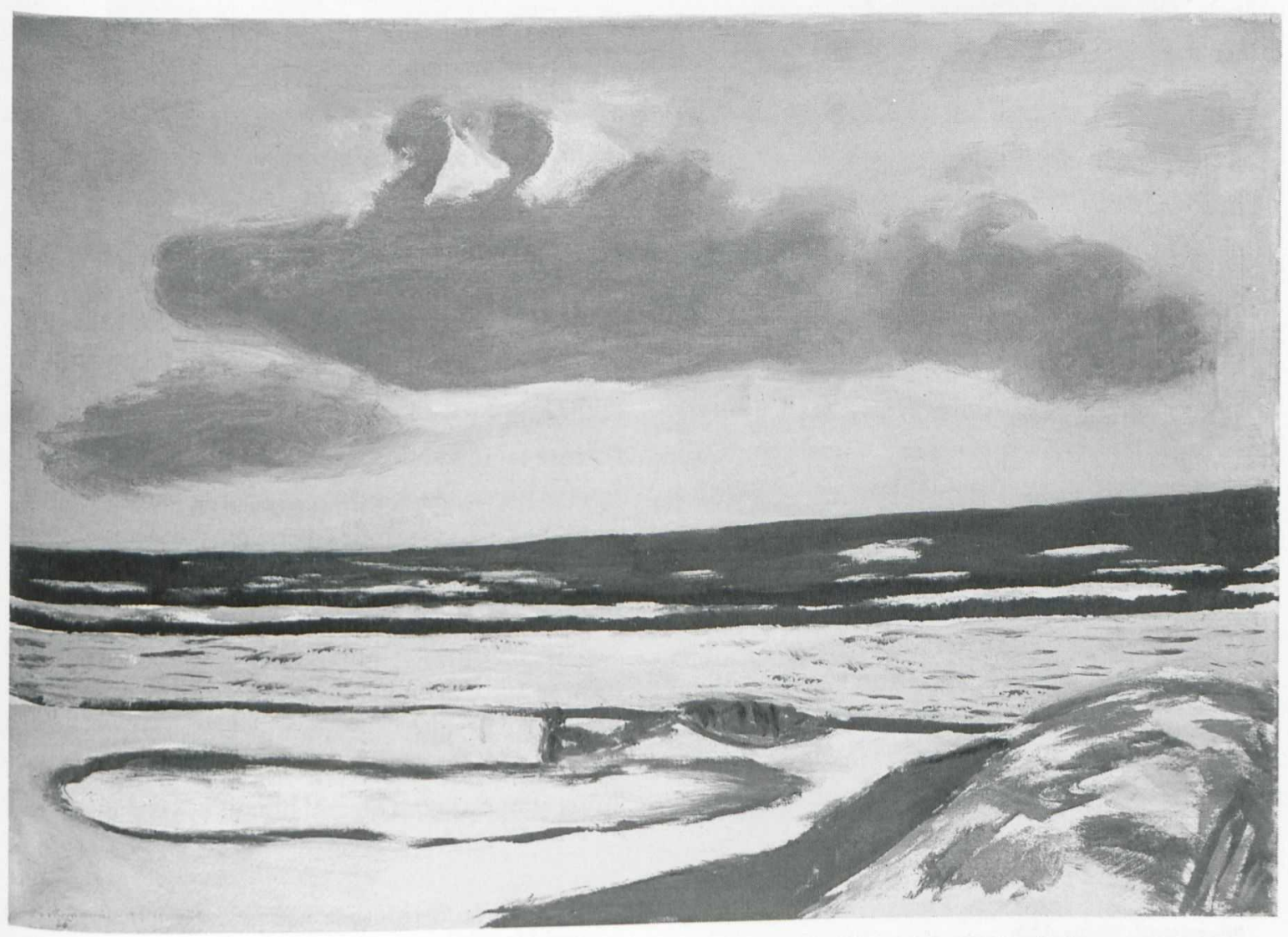

16. Max Beckmann: Meereslandschaft mit Boot, 1936, Köln, Museum Ludwig 


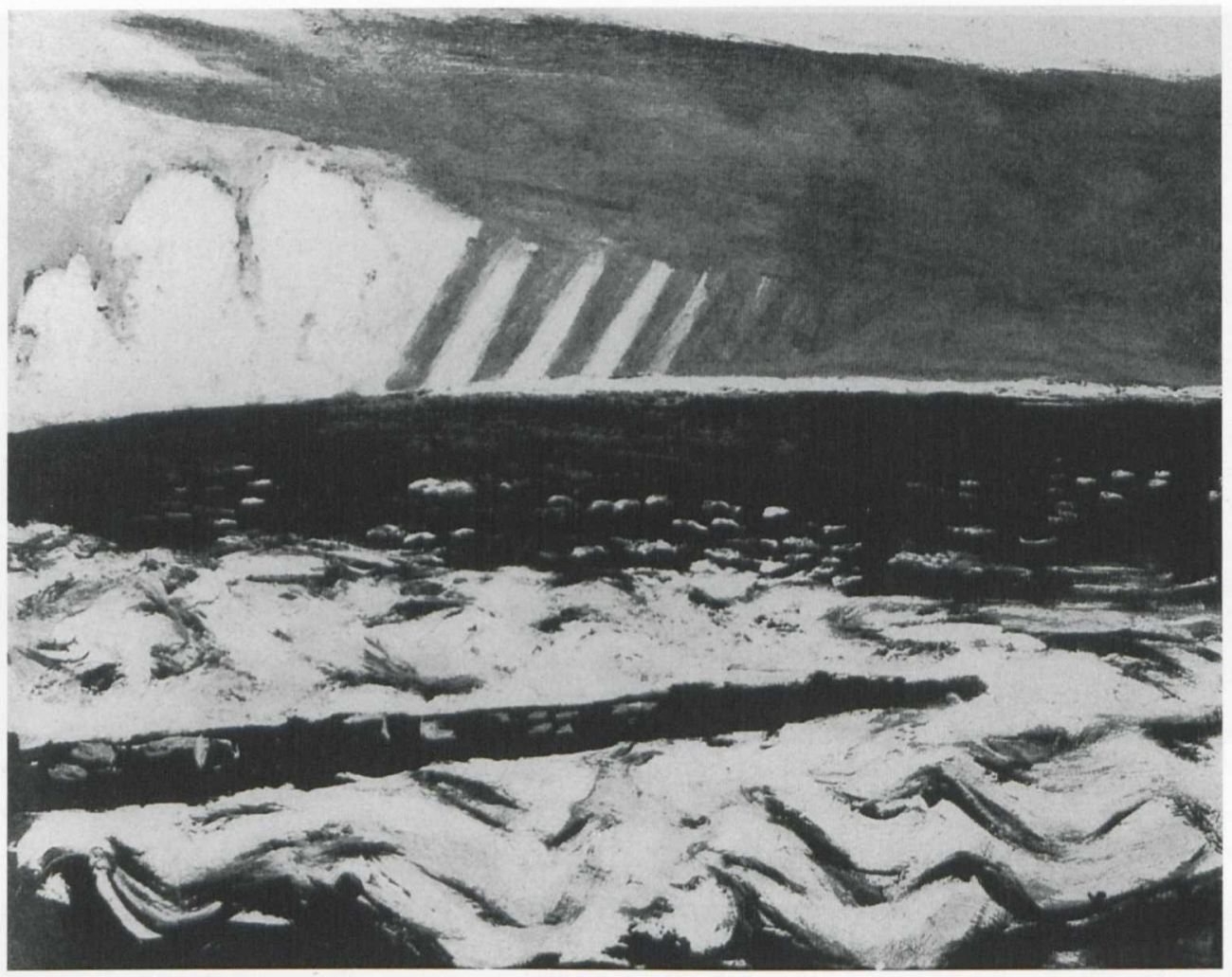

17. Max Beckmann: Nordsee I Wangerooge, 1937, Slg. Stephan Lackner

Schicksals gemacht hat, ob das dramatische Teilstück der Meeresküste wirklich für die Bedrohung durch die N.S.-Diktatur stehen kann. Das Gemälde war noch im Jahr 1936 öffentlich zu sehen - in der Ausstellung »Deutscher Kunst im Olympiajahr « in Hamburg im dortigen Kunstverein, die der Deutsche Künstlerbund organisiert hatte. Am 2I.Juli 1936 wurde diese Ausstellung unter dem Titel "Malerei und Plastik in Deutschland 1936" eröffnet, jedoch durch Adolf Ziegler, den Präsidenten der NS-Reichskulturkammer, am 3I.Juli wieder geschlossen. Ziegler schrieb an Georg Kolbe, ${ }^{\text {,I }}$ $\mathrm{da}$ die Ausstellung "jegliche Verantwortung gegenüber Volk und Reich vermissen « lasse. Im übrigen wurde der Deutsche Künstlerbund, gegrün-

${ }^{51}$ Siehe Kat. »1936 Verbotene Bilder « (wie Anm. 49) 1986, 96-99 und 28-29 Abb.

52 Vgl. Carl Einstein, Die Kunst des 20. Jh. (wie Anm. 23) det 1904 von Kalckreuth, Klinger, Graf Keßler u.a., daraufhin von den Nazis verboten.

Im Jahre 1935 auf 1936 malte Beckmann eine querformatige "Meeres-Landschaft mit Boot" am Ufer (Museum Ludwig, Köln, Abb. I6), die ohne Zweifel eine feine Symbolik auf die Sehnsucht nach rettender Ferne ausdrückt: Ein schräg gemalter Meeresstrand ist gestaffelt über eine Düne rechts im Vordergrund in die Tiefe mehrerer Wasserzonen und einen malvenfarbigen Himmel, an dem eine merkwürdig geformte Wolke die Sonne verdunkelt, ja zu bedrohen scheint. Dem Betrachter fällt das kleine braune Boot im Vordergrund auf, Gerät und Symbol möglicher, aber unsicherer Entfernung (Flucht) vom Strand hinaus auf das unsichere

I93I, I8I-I84; Beckmanns Satz zitiert nach »Sichtbares und Unsichtbares« (wie Anm. 40), 1965, 22. 


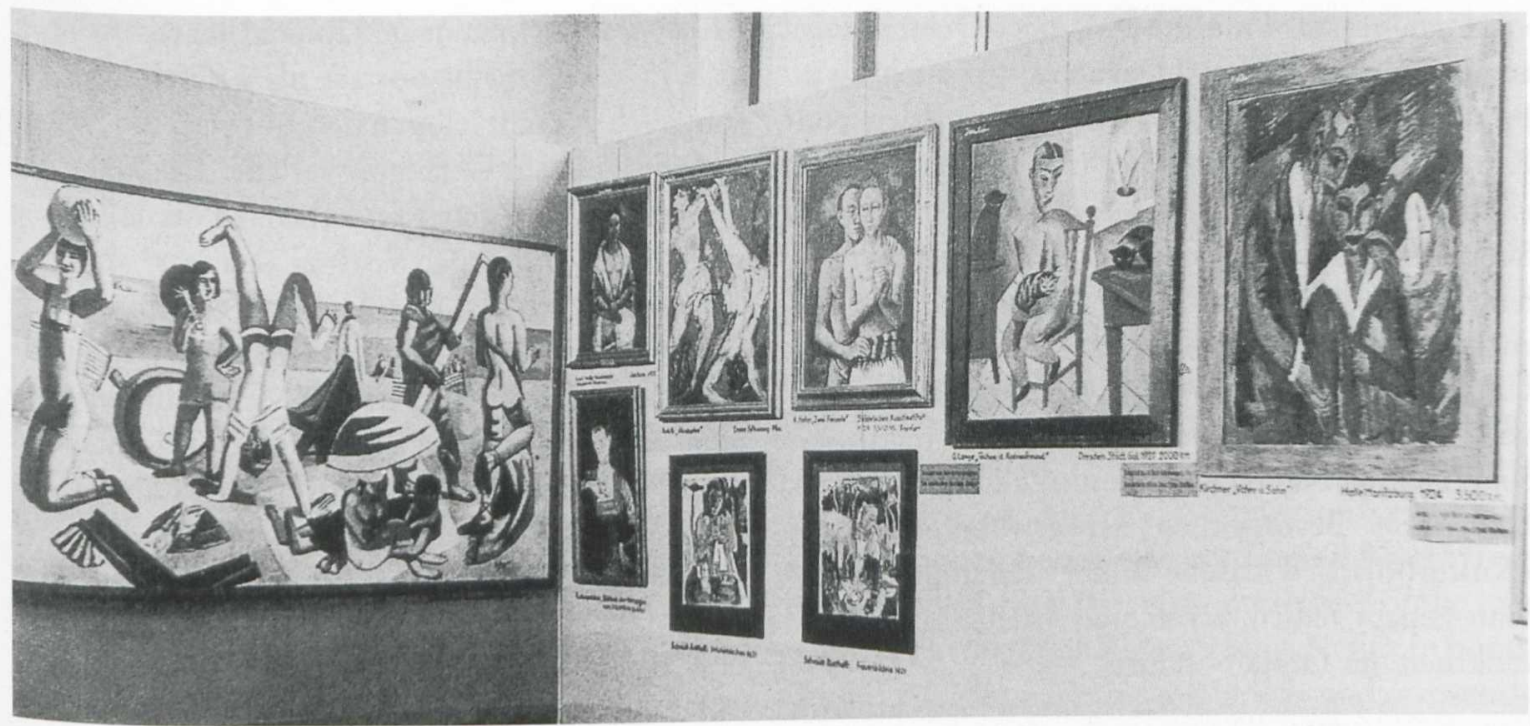

18. Max Beckmann: Strandbild 1927, ehem. Frankfurt, Städelsches Kunstinstitut, 1937 in der Ausstellung »Entartete Kunst«, München, verschollen

Meer. Über die Sachlichkeit der Wiedergabe des Sichtbaren hat Beckmann sowohl in diesem Boot als auch in der tierkopfartig gemalten Wolkenformation Hinweise eingewoben auf unsichtbare Sinn-Dimensionen und somit seiner generellen Kunstforderung entsprochen, das fotografisch Sichtbare mit Phantasie und Gestaltung zu übersteigen, im Sichtbaren das Unsichtbare (mit) anschaulich wirken zu lassen, bzw. "Das Unsichtbare sichtbar machen durch die Realität« (Vortrag London 1938) - "Das mag vielleicht paradox klingen - es ist aber wirklich die Realität, die das eigentliche Mysterium des Daseins bildet! « ${ }^{2}$

Seinen Traum - »Imaginationen des Raumes «realisierte Beckmann nochmals im Mai-Juni 1937, vor der Flucht nach Amsterdam im Juli, in einer Art Triptychon von See-Stücken bei Wangerooge. Diese Gemälde befinden sich in der Slg. Stephan Lackners: »Nordsee I mit Gewitter «, (Abb. 17 $)^{53}$ wieder ein stark gewölbter Horizont, der das dunkle, vorn gischtende Meer begrenzt, darüber ein aufbrechender Himmel, an dem eine blaue Ge-

\footnotetext{
${ }^{53}$ Der »Nordsee «-Zyklus von 1937 bei Göpel (wie Anm. 14), Katalog no. 464-469; $»$ Nordsee I* war in der Retrospektive, München 1984 , no. 76 zu sehen; »Nordsee
}

witterwand abzieht; und $»$ Nordsee $I I I$ « von strahlendem Ausdruck, das die Schönheit des Meeres preist.

Zu den drei Wangerooge-Bildern kommen Küstenstücke von Holland, die auch 1937 entstanden und die allesamt das Heraklitische des Meeres zeigen. Beckmann scheint trotz des "Meeresstrandes mit Boot" von 1936 und trotz allem Pessimismus', zu dem die zoer Jahre Anlaß gaben, sich nicht existentiell bedroht gefühlt zu haben, - wie Kokoschka oder Ernst Barlach, von politischen Künstlern wie George Grosz ganz zu schweigen. Erst als die Nazis die Propaganda-Schau der "Entarteten « installiert hatten und Hitler seine Rede zur Eröffnung des Hauses der »Deutschen Kunst« im Juli 1937 hielt, flüchtete Beckmann nach Holland.

Bei Eröffnung der »Entarteten « hingen von Beckmann etliche Werke in München bzw. in dieser N.S.-Wanderausstellung, - so die "Krenzabnabme" aus dem Städel in Frankfurt/M., "Christus und die Ehebrecherin " aus der Kunsthalle Mannheim, die »Nizza«-Ansicht und die

III , 1937 ( $59 \times 77 \mathrm{~cm})$ no. 4 in: Katalog Max Beckmann - Sammlung Lackner, Bremen/Berlin/Luzern 1967/68. 
"Saxophone" aus Frankfurt/M., der "Ochsenstall aus Berlin u. a. Bilder. ${ }^{54}$ Darunter war auch im 4. Raum des Obergeschoßes neben Gemälden von Kirchner, Hofer, Felixmüller und Kokoschka das $170 \times 300 \mathrm{~cm}$ große Strandbild von 1927 aus der Städtischen Galerie Frankfurt/M. (heute verschollen, Abb. I8) ${ }^{55}$. Dieses Werk war eine Weiterführung der Thematik des "Lido«-Bildes von 1924. Und besonders dieses Gemälde mit den grotesk verfremdeten Menschen am Strand mag der Schreiber der Neuen Mannheimer Zeitung vom I3. 4. 1933 bei Besprechung der erwähnten Schau "Kulturbolschewistische Bilder« (Mannheim) im Sinn gehabt haben, als er von "seelenloser Verrenktheit der Gestalt« schrieb.

${ }^{54}$ Franz Roh, »Entartete Kunst«, Hannover 1962; Andreas Hüneke, Max Beckmann und die faschistische Aktion »Entartete Kunst«, in: Katalog Leipzig (wie Anm. 9), hg. von Dieter Gleisberg, 1984, 5If.; Mario v. Lüttichau, Rekonstruktion der »Entartete Kunst «, in: Die Kunststadt München 1937, München 1987, I2off. und derselbe in: Degenerate Art, ed. S. Barron, Los Angeles 1991, deutsche Ausgabe 1992, Abb. Seite 59; Zum "Ochsenstall $\star$ vgl. besonders G. Bauer: Braune
Als Max Beckmann in Holland lebte, malte er sich in einem Selbstporträt als »Befreiter ", der (obgleich er nicht leiblich bedroht war) die Ketten in der Hand, ein Gefängnis verläßt. Die Nähe des Meeres mag ihn getröstet haben. In diesem Sinne sagte er im Londoner Vortrag von 1938: »Ich bin oft - sehr oft allein. Das Atelier in Amsterdam ... füllt sich aufs Neue mit Figuren aus alter und neuer Zeit, und immer spielt das Meer von nah und weit durch Sturm und Sonne in meine Gedanken. Dann verdichten sich die Formen zu Dingen, die mir verständlich erscheinen in der großen Leere und Ungewißheit des Raumes, den ich Gott nenne.«

Rindviecher, in: Wallraf-Richartz-Jahrbuch 52, 1991, $331 f$.

ss C. Lenz, Beckmann und Italien (wie Anm. 23), 1976, 28; Mario von Lüttichau (wie Anm. 54) 1987, I42; derselbe in: »Entartete Kunst « (wie Anm. 54) 1992, 58; zur Hängung des "Strandbildes « März-April 1938 in Berlin siehe auch das Foto bei Andreas Hüneke, Weimarer Funde, in: Neue Zeitschrift für bildende Kunst 2/1995, AprilMai, Is.

Abbildungsnachweis: 10, I3 Bayerische Staatsgemäldesammlungen München. - 4, 6, 7, 17, 18 Verfasser. - I5 Städel, Frankfurt/M. - I Leipzig, Museum der bildenden Künste. - 3 Regensburg, Museum Ostdeutsche Galerie. 2, 5, 8 Kat. Meisterwerke, Stuttgart 1994. - 9 Weimar, Kunstsammlungen (L. Held). - 6 Köln, Rhein. Bildarchiv. - II Berlin, Villa Grisebach. - I2 Mannheim, Kunsthalle. 